\title{
The high-bar and low-bar back-squats: A biomechanical analysis
}

Daniel J Glassbrook ${ }^{1}$, Scott R Brown ${ }^{1}$, Eric R Helms ${ }^{1}$, J Scott Duncan ${ }^{1}$, Adam G Storey ${ }^{1,2}$

${ }^{1}$ Sports Performance Research Institute New Zealand (SPRINZ), Auckland University of Technology, Auckland, New Zealand

${ }^{2}$ High Performance Sport New Zealand (HPSNZ), Auckland, New Zealand

Brief running head: High-bar vs Low-bar squats

\section{Abstract word count: 218}

Word count excluding tables and references: 6900

Number of tables: 13

Number of figures: 2

Category: Original research

Date of journal submission: 09 September 2016

Resubmission date: 24 December 2016

Corresponding author: Daniel J Glassbrook, Sports Performance Research Institute New Zealand (SPRINZ), Auckland University of Technology, 17 Antares Place, Level 2, Mairangi Bay, Auckland, New Zealand 0632, Phone: (+64) 279565101, Fax: (+64) 99219960, Email: daniel.glassbrook@aut.ac.nz 


\section{ABSTRACT}

No prior study has compared the joint angle and ground reaction force $(F v)$ differences between the high-bar back-squat (HBBS) and low-bar back-squat (LBBS) above 90\% 1RM. Six male powerlifters (height: $179.2 \pm 7.8 \mathrm{~cm}$; bodyweight: $87.1 \pm 8.0 \mathrm{~kg}$; age: $27.3 \pm 4.2$ years) of international level, six male Olympic weightlifters (height: $176.7 \pm 7.7 \mathrm{~cm}$; bodyweight: $83.1 \pm 13 \mathrm{~kg}$; age: $25.3 \pm 3.1$ years) of national level, and six recreationally trained male athletes (height: $181.9 \pm 8.7 \mathrm{~cm}$; bodyweight: $87.9 \pm 15.3 \mathrm{~kg}$; age: $27.7 \pm 3.8$ years) performed the LBBS, HBBS, and both LBBS and HBBS (respectively) up to and including 100\% 1RM. Small to moderate $(d=0.2-0.5)$ effect size differences were observed between the powerlifters and Olympic weightlifters in joint angles and $F v$, although none were statistically significant. However, significant joint angle results were observed between the experienced powerlifters/weightlifters and the recreationally trained group. Our findings suggest that practitioners seeking to place emphasis on the stronger hip musculature should consider the LBBS. Also, when the goal is to lift the greatest load possible, the LBBS may be preferable. Conversely, the HBBS is more suited to replicate movements that exhibit a more upright torso position, such as the snatch and clean, or to place more emphasis on the associated musculature of the knee joint.

KEY WORDS: Joint angles; ground reaction forces; EMG; powerlifting; Olympic weightlifting 


\section{INTRODUCTION}

The squat is one of the most common exercises in strength and conditioning. The movement is widely accepted as valid and reliable for the assessment, and improvement of lowerextremity/trunk strength, function, and resilience to injury $(4,9,10)$, as well as an effective exercise in injury rehabilitation (19). These benefits are possible through the contributions of the quadriceps, hamstrings, gluteal, triceps surae, and lumbar erector muscle groups to the completion of the movement $(9,25)$. In fact, it is predicted that more than 200 muscles are active throughout the completion of a single repetition $(31,36)$. The squat itself is in essence a simple movement, despite the great number of active muscles throughout. In strength and conditioning, load can be applied to the squat movement via several methods, for example dumbbells, kettlebells, and a range of other weighted implements. However, perhaps most commonly load is applied via a barbell, and in one of two ways: 1) as a front-squat, where a barbell is placed anteriorly on the shoulder and 2) as a back-squat, where the barbell is placed posteriorly to the shoulder and across the trapezius musculature (16). The focus of this article will be the back-squat.

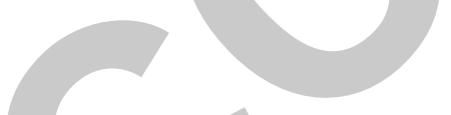

There are two different variations of the back-squat, differentiated by the placement of the barbell on the trapezius musculature. The traditional "high-bar" back-squat (HBBS) is performed with the barbell placed across the top of the trapezius, just below the process of the C7 vertebra, and is commonly used by Olympic weightlifters to simulate the catch position of the Olympic weightlifting competition lifts; the snatch and clean and jerk (41). Conversely, the "low-bar" back squat (LBBS) places the barbell on the lower trapezius, just over the posterior deltoid and along the spine of the scapula (41). The LBBS is commonly used in competitive powerlifting (where the back-squat is one of the three competition lifts), as it may enable higher loads to be lifted (32). This could be due to the maximization of 
posterior displacement of the hips, and increased force through the hip joints in comparison to the knee joints (37). The differences in bar position between the HBBS and LBBS result in an altered center of mass. Therefore, movement strategies result in order to maintain the bodies center of mass within its base of support. These movement strategies may manifest as: changes in 1) joint angles of the lower extremity kinetic chain and, 2) ground reaction forces $(F v)$.

When comparing the HBBS to LBBS, several differences present themselves. In powerlifting, there are competition regulations that each lifter must comply with in order for each lift to count towards their competition total (21). One such regulation is for sufficient 'depth' to be reached in the squat. That is, there must be sufficient flexion of the knees and lowering of the hips towards the ground, so that "the top surface of the legs at the hip joint are lower than the top of the knees" (21). In comparison, the HBBS is not directly included as a competition lift in Olympic weightlifting. Therefore, in training Olympic weightlifters typically squat to a depth that replicates the final catch position of the snatch and clean and jerk. This often manifests as a deeper squat position than powerlifting regulation depth, characterized by greater flexion at the hip, knee and ankle joints. Prior research has shown that the angle at peak knee flexion is generally smaller in the HBBS (e.g. $70-90^{\circ}$ ), in comparison to the LBBS (e.g. 100-120 $)(5,11,13,17,18,20,24,27,37,38)$. Interestingly, some studies have reported the reverse $(17,24,37)$. These conflicting results (although not explicitly stated by the authors), are likely to be the raw joint angles and not the actual angle (Figure 1).

**Figure 1 around here** 
Moreover, prior research specifically comparing the HBBS to the LBBS shows that the LBBS is defined by a smaller absolute trunk angle, and therefore greater forward lean in order to maintain the barbell over the center of mass $(2,14,41)$. The unique position of the LBBS results in 1) a decreased trunk lever arm when placing the bar lower on the back, 2) a greater emphasis on the stronger musculature of the hip rather than the musculature of the knee joint and, 3) an increase in stability and a potential decrease in stress placed on the lumbar region and ankle, when compared to the $\operatorname{HBBS}(34,37)$. These factors may contribute to understanding why the LBBS typically allows for greater loads to be lifted. However, these kinematic findings are not definitive and there are mixed results in the literature for the size of HBBS and LBBS trunk angles at peak hip flexion $(5,11,13,17,20,24,27,29,37)$. Similarly, no conclusive differences between the HBBS and LBBS ankle joint angles can be drawn, in reference to prior literature $(13,17,24,34,37)$.

As the position of the barbell on the trapezius influences the joint angles of the back-squat, there is also a resultant influence on the $F v$ produced. The position of the upper body (i.e. hip joint angle) has a large impact on the location and magnitude of the resultant $F v$ due to its larger mass. Due to the LBBS tending to allow for greater loads to be lifted, it would be expected that the $F v$ produced would be greater than with the HBBS. However, the two studies which have specifically compared the $F v$ profiles of the HBBS and LBBS, provide contradictory results to this expectation $(15,37)$. The results of these two studies may indicate that, although the LBBS typically allows for greater load to be lifted through apparent mechanical advantages such as a decreased trunk lever arm, these mechanical advantages are not effectively displayed by $F v$. Furthermore, the results of these studies specifically may have arisen due to the level of expertise of the participant with performing the LBBS as the authors chose to target the HBBS in recruitment, as the focus for expertise. 
Therefore, further research is warranted to understand the $F v$ differences between the HBBS and LBBS, in particular with loads greater than 90\% 1RM.

The existing literature provides some insight into the kinematic and kinetic differences between the HBBS and LBBS. However, there is no consensus as to the differences between the two back-squat barbell positional variations. At present, no prior study has compared the joint angles and $F v$ of the HBBS and LBBS above 90\% 1RM and some results may have been confounded by inadequate familiarization. Thus, the purpose of this study was to compare and contrast the differences in joint angles and $F v$ of the HBBS and LBBS, up to and including maximal effort, in an effort to create a full profile of the two BBS variations in groups both well versed and newly introduced to these movements. The results of this investigation will add to the current body of knowledge of Olympic weightlifting and powerlifting practice alike, as well as providing an understanding of why the LBBS may allow for a greater load to be lifted.

\section{METHODS}

\section{Experimental Approach to the Problem}

In order to determine why the LBBS may allow for greater loads to be lifted than the HBBS, both squat styles were performed by experienced and in-experienced lifters. The HBBS was performed by experienced Olympic weightlifters, and the LBBS by experienced powerlifters, up to and including $100 \%$ of $1 \mathrm{RM}$. Recreationally trained athletes served as a comparison group and performed both the HBBS and LBBS. It is assumed that the experienced Olympic weightlifters and powerlifters have a better technique than the recreationally trained athlete, 
however it is important to acknowledge this may not be strictly true in practice. A profile of each squat was created through analysis of kinematic joint angles and kinetic $F v$ differences.

\section{Subjects}

Six male powerlifters (height: $179.2 \pm 7.8 \mathrm{~cm}$; bodyweight: $87.1 \pm 8.0 \mathrm{~kg}$; age: $27.3 \pm 4.2$ years) of international (i.e. Oceania championships) level volunteered to participate in the LBBS group. In addition, six male Olympic weightlifters (height: $176.7 \pm 7.7 \mathrm{~cm}$; bodyweight: $83.1 \pm 13 \mathrm{~kg}$; age: $25.3 \pm 3.1$ years) who had previously qualified for national championship level competition volunteered to participate in the HBBS group. All powerlifters routinely performed the LBBS in training and competition, and all Olympic weightlifters routinely performed the HBBS in training. Finally, six recreationally trained male athletes (height: $181.9 \pm 8.7 \mathrm{~cm}$; bodyweight: $87.9 \pm 15.3 \mathrm{~kg}$; age: $27.7 \pm 3.8$ years) volunteered as a comparison group and each participant was required to perform both the LBBS and HBBS in a randomized order, after two familiarization sessions with both types of squat. All participants were free of injury and had $\geq 1$ year's strength training experience (powerlifters: $5.05 \pm 4.56$ years; Olympic weightlifters: $3.75 \pm 2.72$ years; recreational: 8.67 \pm 3.5 years) consisting of $\geq 3$ training sessions per week for the powerlifters and Olympic weightlifters. The comparison group volunteers were required to train the back-squat in $\geq 1$ training sessions per week. Due to small participant numbers ( $n=6$ for each group), the results of this study may not provide a full representation of the differences between each squat type. Some differences may be due to sampling error.

Prior to testing, written informed consent was received from each participant and all testing conditions were examined and approved by the Auckland University of Technology Ethics Committee (14/398). 


\section{Procedures}

\section{Powerlifters and Olympic weightlifters}

The powerlifters (POW) and Olympic weightlifters (OLY) were required to attend only one session of approximately three hours in duration. A full 'level two' anthropometric assessment was performed on all athletes by an experienced International Society for the Advancement of Kinanthropometry (ISAK) anthropometrist followed by a LBBS 1RM test for the POW, and a HBBS 1RM test for the OLY.

\section{Comparison group}

The recreationally trained athletes $(\mathrm{COM})$ were required to attend four separate sessions over the course of one week: two guided one-hour familiarization sessions, one personal familiarization session and one three-hour long testing session (Figure 2). The first familiarization session comprised of the 1RM testing protocol for HBBS and LBBS with loads up to $60 \%$ of self-reported or predicted 1RM. Self-reported 1RM values (performed within the last six months) for either back-squat variation were used to estimate load progressions. Pilot testing determined that the load of the unknown back-squat variation would be around $90 \%$ of the known back-squat $1 \mathrm{RM}$ regardless of which squat style was routinely performed. Thus, the loads for the familiarization session were estimated from one known 1RM for one back-squat variation and a predicted 1RM at 90\% of the known 1RM. The second familiarization session was performed two days later and comprised the same HBBS and LBBS protocol in the same order as the first familiarization session, up to $80 \%$ $1 \mathrm{RM}$ of the self-reported and predicted $1 \mathrm{RM}$ for either back-squat variation. 
**Figure 2 around here**

In both the first and second familiarization sessions for each participant, the resistance exercise-specific rating of perceived exertion (RPE) scale (43) (appendix 7) was used to ensure that intensity and predicted attempt weight values were correct. In the first familiarization session, an RPE value of 3 or less (i.e. "light to little effort") was expected to be reported in line with the percentages of the $1 \mathrm{RM}(50$, and $60 \%)$. If this was not achieved, the predicted weight values were changed for the second familiarization session. In the second familiarization session, the same RPE values of 3 or less were employed for the $50 \%$, and $60 \%$ of predicted 1RM sets. After that, a self-reported RPE of 5 or less (i.e. "light effort with at-least 6 more repetitions possible") was expected for the 70\%, and $80 \%$ of 1RM sets. If these RPE values were not achieved, the predicted 1RMs for both back-squat variations were changed for the final testing session. In the period between the second familiarization session and final testing session, a self-directed familiarization session was included for each participant to re-inforce the skills learned in the previous familiarization sessions, and to provide a chance to practice each bar position prior to the testing. Each participant was asked not to exceed an RPE of 5 in this session, and to do no more than three sets. The final testing session was performed three days later and comprised of a full anthropometric assessment, followed by a 1 RM test of both the HBBS and LBBS in random order so that half of the comparison group performed the HBBS first, and the other half performed the LBBS first. This randomized order was employed to minimize any fatigue affect from performing two maximal squat tests in one testing session. 


\section{Back-squat 1RM testing protocol}

All squats were completed in line with the International Powerlifting Federation's competition rules (21). Both the HBBS and LBBS were deemed to be successful lifts if the athlete was able to safely lower the bar to a minimum accepted depth (the top surface of the legs at the hip joint are lower than the top of the knees) or lower, through a bending of the knees, and then recover at will to a stance with knees locked, without the aid of any spotters. The OLY participants were instructed to squat to the usual depth they perform in training. Specific focus was placed on ensuring correct depth was obtained, the legs were completely locked out at the conclusion of each repetition, and no downward movement was observed on the ascent.

Prior to testing, each participants beltless 1RM was estimated. If in normal training, the participant did not use a weight belt, the athlete's predicted beltless 1RM was used. If the participant used a weight belt in normal training, and had a known belted 1RM, this belted 1RM was used to predict the athletes beltless 1RM. Pilot testing determined that the beltless $1 \mathrm{RM}$ is approximately $90 \%$ of a belted $1 \mathrm{RM}$. Weightlifting shoes (comprised of a hard sole and slightly raised heel) were required to be worn by all participants and the heel height was required to be within the range of 1.5-2.0 centimeters. All participants were accustomed to wearing weightlifting shoes. No other supportive aids beyond the use of wrist wraps were allowed to be worn during the test. Before all testing procedures, each participant completed a standardized dynamic warm up.

The 1RM testing protocol was adapted from Matuszak, Fry, Weiss, Ireland and McKnight (26), and consisted of the participants performing 8 repetitions at $50 \%$ of the predicted $1 \mathrm{RM}$, 3 repetitions at $60 \%, 2$ repetitions at $70 \%$, and 1 repetition at 80 , and $90 \%$. Additional warm 
up sets, prior to the initial 8 repetition set with $50 \% 1 \mathrm{RM}$, were permitted with $<50 \% 1 \mathrm{RM}$ load if the participant desired to do so as to better replicate their normal warm up procedures. After the $90 \%$ of predicted 1RM lift, the participant was consulted as to what weight they would like to attempt for a maximal 1RM lift. An experienced strength coach along with the use of a Gymaware Powertool (Kinetic Performance Technology, Canberra, Australia) to measure the mean concentric velocity of the movement, assisted athletes in attempt selection to get as close to a true beltless $1 \mathrm{RM}$ as possible. Prior research has shown that maximal squat attempts performed by experienced lifters are typically performed at approximately 0.2 $\mathrm{m} \cdot \mathrm{s}^{-1}\left(0.24 \pm 0.04 \mathrm{~m} \cdot \mathrm{s}^{-1}\right)(43)$. Commonly a lift at $95 \%$ 1RM was performed prior to attempting the predicted maximal 1RM. After each successful attempt, small weight increments $(1-5 \mathrm{~kg})$ were made in order to obtain a true maximum. Between 3 and 5 minutes' rest was allowed between sets before the next weight was attempted.

\section{Biomechanical instrumentation}

Two embedded force platforms (Model AM6501, Bertec Corp., Columbus, Ohio, USA), were used to collect all kinetic squat data at a sampling rate of $1000 \mathrm{~Hz}$. The kinetic variables of interest included mean bar velocity $\left(\mathrm{m}^{-1} \mathrm{~s}^{-1}\right)$; peak $F v\left(\mathrm{~N} \cdot \mathrm{kg}^{-1}\right) ;$ RFD $(0-50 \mathrm{~ms})\left(\mathrm{N} \cdot \mathrm{s}^{-1}\right)$; RFD $(0-100 \mathrm{~ms})\left(\mathrm{N} \cdot \mathrm{s}^{-1}\right)$; , for both the eccentric and concentric phases. The RFD variables were chosen in line with previous squat research (8). Mean bar velocity was chosen over peak bar velocity for a better representation of each athlete's ability to move load throughout the whole lifting phase (concentric/eccentric) (22). RFD is the change in force over a given time (33), and the eccentric phase of each movement is where the body lowers and slows to a point of zero velocity, immediately prior to the start of the concentric ascent. The eccentric RFD is measured in the time before this change from the eccentric phase to the concentric phase. The two force platforms were arranged next to each other in the middle of the collection space to 
increase the chances of obtaining complete foot contact from each foot during the required movements. Kinematics were collected by nine infra-red cameras (T10S, Vicon Motion System Ltd., Oxford, UK) strategically placed around the force platforms in the collection space. The cameras were arranged so that each marker was always visible to a minimum of three cameras to allow for reconstruction of three-dimensional trajectories. The collection space was calibrated with an error of no greater than 0.2 (route mean squared in camera pixels; the difference between the 2D image of each marker on the camera sensor and the 3D reconstructions of those markers projected back to the cameras sensor) for each camera prior to each data collection session and a point of origin was positioned at the corner of one of the force platforms to establish a local relationship between the camera positions and the laboratory origin. Data from eight reflective markers $(10 \mathrm{~mm}$ diameter) placed in specific locations were used to analyze bar path and joint angles throughout the squat movement using Vicon Nexus software (Version 1.8.5, Vicon Motion System Ltd., Oxford, UK). The joint angles were calculated as the angle between a parent segment (i.e. thigh or femur) and a child segment (i.e. shank or tibia). Markers were placed in the center of both ends of the barbell and on the right side of the athletes' bodies in specific anatomical locations following previous research (28) (Figure 1). The markers were placed on the following locations: acromion process, greater trochanter, lateral epicondyle of the femur, lateral malleolus, top of the heal lift of the lifting shoe and in-line with the lateral malleolus and base of the fifth metatarsal to create five rigid segments. 


\section{Data reduction}

Subsequent to the testing sessions, the two force platforms were combined and all data were filtered with a low-pass fourth-order zero-lag Butterworth filter using a cut-off frequency of $16 \mathrm{~Hz}$ ENREF 12 in a custom-made LabVIEW program (Version 14.0, National Instruments Corp., Austin, TX, USA) based on residual analysis and visual inspection of the kinematic and kinetic data. Kinematic variables of interest were gathered through an individual analysis within the start and finish of the squat to calculate the range-of-motion (peak flexion - initial or finishing flexion) and peak flexion angles for the hip, knee and ankle joints. Peak joint flexion was recorded as the angle at the lowest point of the lift, and peak extension at the highest point of the lift. The hip range-of-motion in the sagittal plane was derived from the anterior angle between the thorax (trunk) and the thigh, the knee range-of-motion was derived from the posterior angle between the thigh and the shank and the ankle range-of-motion was derived from the angle between the shank and the foot. In all cases, the actual angle is presented as opposed to the raw angle (see Figure 1). To obtain kinetic variables of interest, all repetitions were individually analyzed during the eccentric phase (from the initiation of a negative [downward] velocity of the right-side bar marker to the instant the marker reached zero velocity [full depth]), and concentric phase (from the initiation of a positive [upward] velocity of the right-side bar marker to the instant the marker reached zero velocity a second time [the top]).

To obtain kinematic variables of interest, all repetitions were individually analyzed within the start and finish of the squat movement to calculate the range-of-motion (peak flexion - initial flexion) and peak flexion angles for the hip, knee and ankle joints. From the sagittal plane, the hip range-of-motion was derived from the anterior angle between the thorax (trunk) and the thigh, the knee range-of-motion was derived from the posterior angle between the thigh 
and the shank and the ankle range-of-motion was derived from the angle between the shank and the foot. In all cases, the actual angle is presented as opposed to, the raw (Figure 1).

\section{Statistical analysis}

Prior to analyses, data were split into four categories according to trials where a single squat was completed and the \%1RM load achieved in testing: (1) $74-83 \%$, (2) $84-93 \%$, (3) $94-99 \%$, and (4) $100 \%$. This was necessary due to the variation in the number of single repetition trials completed before a true $1 \mathrm{RM}$ was achieved between participants. If multiple trials were completed within a $1 \mathrm{RM}$ range for a participant, the results were averaged so each participant effectively had one trail per category. Generalized linear mixed models using a normal distribution with an identity link and unstructured covariance structure were used to estimate the difference in outcome variables between bar height and subject group across all four load groups while adjusting for the random effect of subject. In an unstructured covariance matrix each variance and each covariance value is estimated uniquely from the data, resulting in the best possible model fit (39). Robust standard errors, constructed using the 'sandwich estimator' of the covariance structure, were used to control for possible misspecifications of the correlation structure. An alpha of 0.05 was used to determine significant associations. Multiple pairwise comparisons were corrected for inflation of Type 1 error using the Bonferroni method (e.g., for all pairwise comparisons in a fixed factor with three groups, significance level was divided by 3). For all variables Cohen's d statistic was calculated as the estimated marginal means divided by the square root of $\mathrm{N}$ multiplied by the Standard Error (i.e. the standard deviation) to provide additional information on the magnitude of the associations, with $0.2,0.5$, and 0.8 representing small, moderate, and large effects, respectively (3). The analysis used IBM SPSS Statistics v. 23.0.0.0 (IBM, Armonk, NY, USA) software. 


\section{RESULTS}

Initially, a comparison of the HBBS performed by the OLY and comparison group (HBCOM), and the LBBS performed by the POW and COM group (LBCOM) was completed to determine if the comparison group data could be combined with the OLY and/or the POW for the high and low bar positions, respectively. Significant joint angle differences were observed in knee flexion $(p=0.04)$, and ankle range of motion $(\mathrm{ROM})(\mathrm{p}=0.04)$ at $100 \%$ of 1RM for HBBS (OLY vs. HBCOM), and in knee ROM ( $p=0.02)$ at $100 \% 1 \mathrm{RM}$ for the LBBS (POW vs. LBCOM). Significant differences for several kinetic variables across all four percentage ranges of 1RM for both HBBS (OLY vs. HBCOM) and LBBS (POW vs. LBBS) were also observed. Therefore, in the following sections, the data has been analyzed with all four groups displayed independently.

\section{Load}

The mean loads are presented in Tables 1 and 2. No significant differences were observed between OLY and POW, and HBCOM and LBCOM. However, on average the POW group lifted greater loads compared to the OLY group across all ranges of load $(\mathrm{d}=0.3,0.2,0.2$ and 0.2 for ranges of $74-83 \%, 84-93 \%, 94-99 \%$, and $100 \% 1 \mathrm{RM}$ respectively). Small effect sizes indicated that greater loads and loads relative to body weight were lifted by the LBCOM than the HBCOM group for the $74-83 \%(d=0.3$ and 0.3 , respectively), and $84-93 \%(d=0.3$ and 0.4 , respectively) $1 \mathrm{RM}$ ranges, but only for load at $100 \% 1 \mathrm{RM}(\mathrm{d}=0.4)$. Moderate effect sizers indicated that greater loads were lifted by the LBCOM in comparison to the HBCOM group at $94-99 \% 1 \mathrm{RM}$ in both load and load relative to body weight $(\mathrm{d}=0.5$ and 0.6 , respectively), and at $100 \% 1 \mathrm{RM}$ in load relative to body weight $(\mathrm{d}=0.5)$. 
**Tables 1 and 2 around here**

\section{Centre of pressure}

The mean distances of the bar from the center of pressure (COP) are presented in Table 3. In the experienced OLY and POW groups, there is a distinct difference between the two bar positions. The LBBS performed by the POW shows a greater average distance from the bar to the COP. In the less experienced COM group, the same difference is generally observed between the HBBS and LBBS, but is much less pronounced.

**Table 3 around here**

\section{Kinematics}

Differences in the estimated marginal means for the kinematic variables are presented in Tables 4 and 5. No significant differences were observed between the OLY and POW groups, in any condition. A significantly larger knee flexion angle was observed in the HBCOM when compared to the OLY group $(p=0.04 ; d=0.7 ; \%$ Diff $=14.3)$ at $100 \% 1 \mathrm{RM}$. Conversely, the OLY group displayed a significantly larger ankle ROM than the HBCOM group at $100 \%(\mathrm{p}=0.04 ; \mathrm{d}=0.07 ; \%$ Diff $=18.3)$. The only significant difference between the POW and LBCOM groups was observed at 100\% 1RM, with the POW group demonstrating a significantly larger knee ROM $(p=0.02 ; d=0.8 ; \%$ Diff $=18.9)$. The majority of significant results were observed between the HBCOM and LBCOM. Significant differences were observed in knee ROM at 74-83\% 1RM $(\mathrm{p}=0.04)$, peak hip flexion at 8493\% 1RM ( $\mathrm{p}=0.02)$, peak hip flexion at 94-99\% 1RM $(\mathrm{p}<0.00)$ and peak hip flexion $(\mathrm{p}<$ $0.00)$, peak knee flexion $(\mathrm{p}=0.01)$, and knee ROM at $100 \% 1 \mathrm{RM}(\mathrm{p}=0.02)$. In all cases the 
HBCOM group displayed larger angles, except for peak knee flexion at 100\% 1RM where the LBCOM was greater. No significant interactions between load and group were detected.

**Tables 4 and 5 around here**

\section{Kinetics}

Kinetic differences in estimated marginal means are presented in Tables 6-13. The only significant difference observed between the OLY and POW groups, across all percentage ranges of 1RM was in the eccentric phase RFD (0-50ms) at 74-83\%1RM $(p=0.03)$. Small effects were observed for a variety of variables across all four ranges of load (\%1RM). Moderate kinetic effects showing a greater OLY RFD were also observed in the eccentric phase of the squat at $74-83 \% 1 \mathrm{RM} 0-50 \mathrm{~ms}(\mathrm{~d}=0.6)$, and $0-100 \mathrm{~ms}(\mathrm{~d}=0.6)$. Moderately larger effects were also observed in the concentric phase in the OLY at 84-93\% 1RM at 0$50 \mathrm{~ms}(\mathrm{~d}=0.6)$, and at $94-99 \% 1 \mathrm{RM}(0-50 \mathrm{~ms})(\mathrm{d}=0.6)$. Only one significant difference between the HBCOM and LBCOM was observed. The HBCOM group produced a significantly greater peak $F v$ in the eccentric phase at 94-99\% $1 \mathrm{RM}(\mathrm{p}=0.05 ; \mathrm{d}=0.9 ; \%$ Diff $=2.4)$, refer to Tables 10 and 11. A large number of significant differences $(\mathrm{p}<0.05)$ were observed across all load ranges, in both the eccentric and concentric phases for OLY vs HBCOM, and POW vs LBCOM (Tables 6, 8, 10, 12). In all cases of significant difference, the more experienced OLY and POW groups produced larger forces than those produced by the less experienced $\mathrm{HBCOM}$ and LBCOM groups respectively.

**Tables 6-13 around here** 


\section{DISCUSSION}

The purpose of this study was to compare and contrast the differences in kinematics and kinetics between the HBBS and LBBS in order to understand why the LBBS might typically allow for greater loads to be lifted (32). Originally the HBBS and LBBS were compared by combining experienced populations (OLY and POW) with the same bar position in resistance trained individuals (HBCOM and LBCOM). However, initial analyses revealed differences between groups using the same bar position (i.e. between HBCOM and OLY, and LBCOM and POW, respectively). Therefore, each group was compared independently in order to examine the kinematic and kinetic differences that arise as a function of bar position (i.e. high-bar and low-bar position) and experience level (i.e. OLY high-bar vs. POW low-bar).

To the best of our knowledge, this is the first study to compare the kinematic and kinetic differences of the HBBS and LBBS using loads $\geq 90 \% 1 \mathrm{RM}$. The main findings of this investigation were; 1) statistically significant results were observed in both joint angles and kinetics between the OLY and HBCOM, and POW and LBCOM groups; 2) although not significant, a small effect size indicated that greater loads were lifted for each of the percentage 1 RM ranges for the LBBS when comparing the POW vs OLY $(d=0.2-0.3)$. In addition, small $(d \geq 0.2)$ and moderate $(d \geq 0.5)$ effect sizes indicated that the LBCOM group lifted greater loads and loads relative to body weight across all ranges of \%1RM; 3) no significant differences were observed in kinematics between the OLY and POW groups, in any conditions, and only one significant difference was observed between the OLY and POW groups in kinetics. However, small $(d \geq 0.2)$, moderate $(d \geq 0.5)$ and large $(d \geq 0.8)$ effects were observed across all ranges of load between OLY and POW; 4) significantly larger joint angles were observed on the HBCOM, in comparison to the LBCOM in knee ROM at 74$83 \%$ and $100 \%$ 1RM, peak flexion at $84-93 \%, 94-99 \%$ and $100 \% 1 \mathrm{RM}$. The LBCOM 
however did produce a larger knee flexion angle at 100\% 1RM, than the HBCOM; 5) only one significant difference was observed between the HBCOM and LBCOM groups in kinetics. The HBCOM group produced a significantly larger peak $F v$ at $94-99 \% 1 \mathrm{RM}$ in the eccentric phase.

Surprisingly, no significant differences were observed between the experienced OLY and POW groups for any joint angles. It was expected that the OLY would display a greater angle at peak hip flexion due to the more upright torso position, and a smaller knee flexion angle. In the present study, small to moderate magnitudes of effect $(\mathrm{d} \geq 0.2-0.5)$ were observed at all four percentages of $1 \mathrm{RM}$, indicating that the OLY group demonstrated a larger hip angle displayed at peak flexion by the OLY group at all percentages of 1RM tested. Prior research by Fry et al., (14) and Wretenberg et al., (41) demonstrated a larger hip angle in the HBBS, and a greater forward lean in the LBBS. However, the squats were only performed at $50 \%$ and 65\% 1RM, respectively, in these aforementioned studies and the results also failed to reach statistical significance. Therefore, it is possible to surmise that OLY consistently demonstrate a larger hip angle and therefore, a more upright torso position when performing the HBBS when compared to the LBBS performed by POW. The knee joint findings of the present study were similar to those reported in other studies $(5,11,13,17,18,20,24,27,37$, 38) and it appears that the OLY displays a smaller peak knee flexion angle (i.e. greater depth) than what is seen during the POW. However, the difference was not pronounced, as there were no significant differences observed but there were small to moderate magnitudes of change $(\mathrm{d} \geq 0.2-0.5)$.

Interestingly however, significant differences were observed in the hip and knee joints, between the HBBS performed by the HBCOM group, and the LBBS performed by the LBCOM. The significant differences between these two groups in joint angles are in line with 
the prior literature, and this indicates that there may have been an influence of experience on the significant results in this study and in the findings of previous research. The smaller hip angle, and greater knee angle shown by the POW group in the present study, indicate a greater posterior displacement of the hip, a more vertical shank, and therefore a greater ankle angle. However, the present study showed no significant differences in ankle joint angles between the OLY and POW groups. Instead, only one significant difference was presented, in the ankle ROM between OLY and HBCOM at 100\% 1RM ( $p=0.04 ; d=0.7 ; \%$ Diff $=18.3)$. Previous investigations have shown no definitive differences between the ankle joint angles of the HBBS and LBBS $(13,17,24,34,37)$. The ankle joint angle results of this study further support these previous findings between experienced populations (i.e. OLY and POW), but may indicate differences in an experienced versus less-experienced groups HBBS practitioners (i.e. OLY and $\mathrm{HBCOM}$ ) at maximal effort.

The upper body has a larger mass than the lower body, and therefore humans are inherently unstable, and require effective control mechanisms to constantly resist perturbation (40). This inherent instability is expressed in three planes of motion when load is added to the upper body via a barbell, as in the case of the HBBS and/or LBBS (35). The COP is the point on the ground at which the $F v$ vector originates, and is a representation of the center of mass (COM) which accounts for the whole body's weight (including the external bar load) (1). It can be argued that the COM/COP will be in the same position with both the HBBS and LBBS, however the variation in position of the bar forces the segments of the body to adapt differently in order to maintain the COM within the athlete's base of support (BOS), and therefore combat a loss of balance. A change in one body segment, will typically result in a change in the other segments (12). The distance of the bar from the COP can help indicate the level of change in these segments, particularly when paired with kinematic joint angle data. 
The results of this study indicate that the mechanisms the body employs to maintain the balance of its system are concentrated at the hip and not at the knee or ankle joint. At the deepest part of each squat, we found the distance of the bar behind the center of pressure (COP) was larger in the LBBS $(55 \pm 39 \mathrm{~mm})$ than in the HBBS $(21 \pm 36 \mathrm{~mm})$ (Table 3$)$. Anthropometric differences (e.g. lower limb length) between participants here would create variability if such a measure was to come from a joint center. Instead the distance from the COP accounts better for the combined mass of the participant and external bar load. These findings exemplify the effects of the low-bar position being further down the back on the lower trapezius musculature, and also indicates a more vertical torso in the HBBS. In order to maintain the position of the barbell on the shoulders and to keep the body's COM within the BOS, the lifter must adopt a smaller torso angle when performing the LBBS. In addition, a wider stance is also often employed when performing the LBBS (10) and anecdotally it is performed to suit the hip structure of the lifter to allow them to obtain the required depth. An increased stance width also acts to effectively increase the BOS, and therefore allows for the bar to be a further distance from the COP, without exiting the BOS. Thus, the smaller hip angle demonstrated in this study may allow greater loads to be lifted with the LBBS, due to the decreased moment arm, greater emphasis on the strong hip musculature, as well as the aforementioned increased stability $(34,37)$.

The only significant difference observed between the OLY and POW groups, across all percentage ranges of $1 \mathrm{RM}$ was in the eccentric phase RFD (0-50ms) at $74-83 \% 1 \mathrm{RM}(\mathrm{p}=$ $0.03)$. However, small $(\mathrm{d} \geq 0.2)$ and moderate $(\mathrm{d} \geq 0.5)$ magnitudes of change were observed for several variables (Tables 7, 9, 11, 13). The OLY and POW that took part in this study were all of a high level and consequently, they lifted loads that were similar to each other when presented relative to body weight, but not in terms of actual load (Table 1 and 2). 
Although not statistically significant, the POW on average lifted greater loads for each percentage of 1RM. Prior research has shown that as load is increased, there is a resulting increase in the $F v$ produced that is proportionate to the increase in load $(6,7,13,23,42)$. With this in mind, it was expected that the results of this study would show that the POW had the ability to generate greater $F v$ levels during the LBBS, due to the larger loads typically lifted. However, this did not occur. Instead, no significant differences were observed between the POW and OLY groups, and only small effects $(\mathrm{d} \geq 0.2)$ were observed for $F v$. These effects are also in direct contrast to Goodin (15), who showed the HBBS to produce larger $F v$, when compared to the LBBS, with loads of 20-80\% 1RM, in HBBS dominant athletes. In the current investigation the $F v$ levels were only shown to be significantly greater in the LBBS than the HBBS between the less experienced HBCOM and LBCOM groups in the eccentric phase at $94-99 \% 1 \mathrm{RM}(\mathrm{p}=0.05 ; \mathrm{d}=1.3 ; \%$ Diff $=2.4)$. This indicates that the LBBS may in fact be a more efficient technique of squatting large loads in proportion to the lifter's bodyweight. Even though greater loads were lifted by the POW, when compared to the OLY for each set, the $F v$ produced was relatively the same, thus the mechanical advantage can be attributed to kinematic joint angle differences. An analysis of the lower limb and trunk muscle activity throughout the squat for both the HBBS and LBBS is necessary to supplement these conclusions. Such an analysis will create a greater understanding as to the level of muscle mass that is deemed to be active throughout each squat style. These findings may provide an insight into the reasons for differing kinetic results, through muscle activity results.

The resistance trained males in this study were recruited as a comparison group and they did not have any specific expertise in either the HBBS or LBBS. As a result, the techniques displayed by the comparison group had many significant kinetic differences when compared 
with the well-trained OLY and POW athletes (Tables 6-13). In addition, significant differences were also observed in several joint angles between the OLY and POW groups versus the HBCOM and LBCOM groups (Table 4 and 5). Therefore, it can be concluded that resistance training experience and technical proficiency have a strong influence on the associated joint angle kinematics and kinetics. Thus, the level of experience of an individual may be a useful predictor of squatting technical performance. This notion, and the results of this study are supported the work of Miletello, Beam and Cooper (30) which reported differences in kinetic and kinematic variables measured at the knee when three different POW groups, of varying experience, performed the LBBS. In order of highest skill to least skilled, the POW groups were: competitive collegiate; competitive high school; and novice. Future studies should look to specifically only include well trained athletes when comparing the HBBS to LBBS, in order to minimize the dilution of results from less experienced populations.

The significant differences observed between the experienced (i.e. OLY and POW) groups and the less experienced (i.e. HBCOM and LBCOM) groups, indicates that the time spent familiarizing each comparison participant with both squat styles was insufficient to create expertise in both styles prior to testing. The differences in joint angles between the two bar positions in the comparison group, can also be attributed to a lack of expertise in both squat styles. Another limitation to this study was the low number of participants representing each group, as this reduced the statistical power of the model. Athletes competing at a high level were targeted to make up the experienced OLY and POW groups (i.e. international and national level, respectively). Therefore, the pool of potential participants was automatically reduced. Moreover, athletes were also recruited from different gyms, in different stages of competition preparation at the time of testing. As a result of the reduced sample size, the 
effect size data should be carefully considered rather than interpreting the findings based on statistical significance alone. Future studies should look to compare larger cohorts of experienced HBBS and LBBS participants up to and including $100 \%$ of $1 \mathrm{RM}$, with the further addition of muscle activity analysis, in order to complete a full profile of each squat style and improve statistical power.

\section{SUMMARY AND PRACTICAL APPLICATIONS}

This study provided evidence to suggest that the LBBS is a more efficient way of squatting large loads, as demonstrated by comparable kinetic results to the HBBS despite greater absolute loads being lifted. This study also indicates that resistance trained individuals should not be compared/combined with well-trained athletes when comparing such a technical movement as the HBBS or LBBS as there is an apparent influence of expertise on the performance of these techniques. With regards to training adaptations, practitioners seeking to place emphasis on the stronger hip musculature should consider the LBBS, as the greater forward lean of the movement ensures the hip muscles are engaged more so than the HBBS. It is also recommended that when the goal is to lift the greatest load possible, the LBBS may be preferable. Conversely, the HBBS is more suited to replicate movements that exhibit a more upright torso position, such as the snatch and clean or to place more emphasis on the associated musculature of the knee joint. Future research should look to analyze the muscle activity differences between the HBBS and LBBS, up to and including 100\% 1RM. The addition of this knowledge to the results presented in this study will provide a complete profile of the differences between the HBBS and LBBS. 


\section{REFERENCES}

1. Benda BJ, Riley PO, and Krebs DE. Biomechanical relationship between center of gravity and center of pressure during standing. Rehabilitation Engineering 2: 3-10, 1994.

2. Benz RC. A kinematic analysis of the high and low bar squat techniques by experienced low bar weight lifters. Pennsylvania: West Chester University, 1989.

3. $\quad$ Cohen J. Statistical power analysis. Current Directions in Psychological Science 1: 98-101, 1992.

4. Cormie P, McGuigan MR, and Newton RU. Adaptations in athletic performance after ballistic power versus strength training. Medicine and Science in Sports and Exercise 42: 1582-1598, 2010.

5. Donnelly DV, Berg WP, and Fiske DM. The effect of the direction of gaze on the kinematics of the squat exercise. Journal of Strength and Conditioning Research 20: 145-150, 2006.

6. Ebben WE and Jensen RL. Electromyographic and kinetic analysis of traditional, chain, and elastic band squats. Journal of Strength and Conditioning Research 16: 547-550, 2002.

7. Ebben WP, Garceau LR, Wurm BJ, Suchomel TJ, Duran K, and Petushek EJ. The optimal back squat load for potential osteogenesis. Journal of Strength and Conditioning Research 26: 1232-1237, 2012.

8. Ebben WP, Kaufmann CE, Fauth ML, and Petushek EJ. Kinetic analysis of concurrent activation potentiation during back squats and jump squats. Journal of Strength and Conditioning Research 24: 1515-1519, 2010.

9. Escamilla RF. Knee biomechanics of the dynamic squat exercise. Medicine and Science in Sports and Exercise 33: 127-141, 2001.

10. Escamilla RF, Fleisig GS, Lowry TM, Barrentine SW, and Andrews JR. A threedimensional biomechanical analysis of the squat during varying stance widths. Medicine and Science in Sports and Exercise 33: 984-998, 2001.

11. Escamilla RF, Fleisig GS, Zheng N, Lander JE, Barrentine SW, Andrews JR, Bergemann BW, and Moorman CT. Effects of technique variations on knee biomechanics during the squat and leg press. Medicine and Science in Sports and Exercise 33: 1552-1566, 2001.

12. Evangelista P and Alberti G. The physics of the squat, in: European Weightlifing Federation Scientific Magazine. 2016.

13. Flanagan SP and Salem GJ. Bilateral differences in the net joint torques during the squat exercise. Journal of Strength and Conditioning Research 21: 1220-1226, 2007.

14. Fry A, Aro T, Bauer J, and Kraemer W. A comparison of methods for determining kinematic properties of three barbell squat exercises. Journal of Human Movement Studies 24: 83, 1993.

15. Goodin J. Comparison of external kinetic and kinematic variables between high barbell back squats and low barbell back squats across a range of loads. Tennessee: East Tennessee State University, 2015.

16. Gullett JC, Tillman MD, Gutierrez GM, and Chow JW. A biomechanical comparison of back and front squats in healthy trained individuals. Journal of Strength and Conditioning Research 23: 284-292, 2009.

17. Hales ME, Johnson BF, and Johnson JT. Kinematic analysis of the powerlifting style squat and the conventional deadlift during competition: is there a cross-over effect between lifts? Journal of strength and conditioning research 23: 2574-2580, 2009. 
18. Han S, Ge S, Liu H, and Liu R. Alterations in three-dimensional knee kinematics and kinetics during neutral, squeeze and outward squat. Journal of Human Kinetics 39: 59-66, 2013.

19. Heijne A, Fleming BC, Renstrom PA, Peura GD, Beynnon BD, and Werner S. Strain on the anterior cruciate ligament during closed kinetic chain exercises. Medicine and Science in Sports and Exercise 36: 935-941, 2004.

20. Hooper DR, Szivak TK, Comstock BA, Dunn-Lewis C, Apicella JM, Kelly NA, Creighton BC, Flanagan SD, Looney DP, and Volek JS. Effects of fatigue from resistance training on barbell back squat biomechanics. Journal of Strength and Conditioning Research 28: 1127-1134, 2014.

21. International Powerlifting Federation. Technical Rules Book 2015.

22. Jidovtseff B, Harris NK, Crielaard JM, and Cronin JB. Using the load-velocity relationship for 1RM prediction. Journal of Strength \& Conditioning Research 25: 267-270, 2011.

23. Kellis E, Arambatzi F, and Papadopoulos C. Effects of load on ground reaction force and lower limb kinematics during concentric squats. Journal of Sports Sciences 23: 1045-1055, 2005.

24. Kobayashi Y, Kubo J, Matsuo A, Matsubayashi T, Kobayashi K, and Ishii N. Bilateral asymmetry in joint torque during squat exercise performed by long jumpers. Journal of Strength and Conditioning Research 24: 2826-2830, 2010.

25. Maddigan ME, Button DC, and Behm DG. Lower-limb and trunk muscle activation with back squats and weighted sled apparatus. Journal of Strength and Conditioning Research 28: 3346-3353, 2014.

26. Matuszak ME, Fry AC, Weiss LW, Ireland TR, and McKnight MM. Effect of rest interval length on repeated 1 repetition maximum back squats. Journal of strength and conditioning research 17: 634-637, 2003.

27. McKean MR, Dunn PK, and Burkett BJ. Quantifying the movement and the influence of load in the back squat exercise. Journal of Strength and Conditioning Research 24: 1671-1679, 2010.

28. McKenzie C, Brughelli M, Whatman C, and Brown S. The influence of optimal handheld load on the technical ability to apply ground reaction forces during horizontal jumping in female netball players. International journal of sports medicine 37: 318-323, 2015.

29. McLaughlin TM, Dillman CJ, and Lardner TJ. Kinematic model of performance in the parallel squat by champion powerlifters. Medicine and Science in Sports 9: 128133, 1977.

30. Miletello WM, Beam JR, and Cooper ZC. A biomechanical analysis of the squat between competitive collegiate, competitive high school, and novice powerlifters. Journal of Strength and Conditioning Research 23: 1611-1617, 2009.

31. Nisell R and Ekholm J. Joint load during the parallel squat in powerlifting and force analysis of in vivo bilateral quadriceps tendon rupture. Scandinavian Journal of Sports Sciences 8: 63-70, 1986.

32. O- Shea P. Sports Performance Series: The parallel squat. National Strength and Conditioning Association Journal 7: 4, 1985.

33. Sands WA, McNeal JR, and Shultz BB. Kinetic and temporal patterns of three types of vertical jump among elite international divers. Research in Sports Medicine: An International Journal 9: 107-127, 1999.

34. Sato K, Fortenbaugh D, and Hydock DS. Kinematic changes using weightlifting shoes on barbell back squat Journal of Strength and Conditioning Research 26: 28-33, 2012. 
35. Schick EE, Coburn JW, Brown LE, Judelson DA, Khamoui AV, Tran TT, and Uribe BP. A comparison of muscle activation between a smith machine and free weight bench press. Journal of Strength and Conditioning Research 24: 779-784, 2010.

36. Stoppani J. Encyclopedia of muscle \& strength. Champaign, IL: Human Kinetics, 2006.

37. Swinton PA, Lloyd R, Keogh JW, Agouris I, and Stewart AD. A biomechanical comparison of the traditional squat, powerlifting squat, and box squat. Journal of Strength and Conditioning Research 26: 1805-1816, 2012.

38. van den Tillaar R, Andersen V, and Saeterbakken AH. The existence of a sticking region in free weight squats. Journal of Human Kinetics 42: 63-71, 2014.

39. West BT, Welch KB, and Galecki AT. Linear mixed models: a practical guide using statistical software. CRC Press, 2014.

40. Winter DA. Human balance and posture control during standing and walking. Gait \& posture 3: 193-214, 1995.

41. Wretenberg P, Feng Y, and Arborelius UP. High- and low-bar squatting techniques during weight-training. Medicine and Science in Sports and Exercise 28: 218-224, 1996.

42. Zink AJ, Perry AC, Robertson BL, Roach KE, and Signorile JF. Peak power, ground reaction forces, and velocity during the squat exercise performed at different loads. Journal of Strength and Conditioning Research 20: 658-664, 2006.

43. Zourdos MC, Klemp A, Dolan C, Quiles JM, Schau KA, Jo E, Helms E, Esgro B, Duncan S, Merino SG, and Blanco R. Novel resistance training-specific RPE scale measuring repetitions in reserve. Journal of Strength and Conditioning Research, 2015.

\section{FIGURE LEGEND}

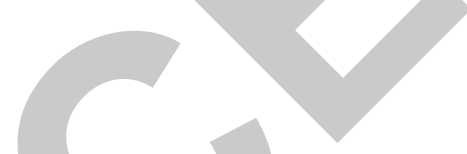

\section{FURE LEGEND}

Figure 1: Actual and raw joint angles of the hip, knee and ankle. Taken from A) the left end of the barbell, B) the right end of the barbell, C) acromion process, D) greater trochanter, E) lateral epicondyle of the femur, F) lateral malleolus, G) the top of the heal lift of the lifting shoe, and $\mathrm{H}$ ) the base of the fifth metatarsal.

Figure 2: Representation of the order of familiarization and testing dates for the comparison group. 
Table 1: Mean loads lifted across all \%1RM ranges

\begin{tabular}{|c|c|c|c|c|c|c|c|}
\hline$\%$ Range & Variable & OLY & POW & HBCOM & LBCOM & OLY vs POW Diff; $\pm 90 \%$ CI & HBCOM vs LBCOM Diff; $\pm 90 \% \mathrm{CI}$ \\
\hline & $\mathrm{BW}(\mathrm{kg})$ & $83.2 \pm 13.0$ & $87.1 \pm 8.0$ & $87.9 \pm 15.3$ & $87.9 \pm 15.3$ & & \\
\hline \multirow[t]{2}{*}{$74-83 \%$} & Load $(\mathrm{kg})$ & $136.6 \pm 23.5$ & $140.9 \pm 20.1$ & $99.9 \pm 13.2$ & 103.0 & & $4.0 \pm 7.6$ \\
\hline & $* \mathrm{BW}$ & $1.6 \pm 0.2$ & $1.6 \pm 0.3$ & $1.2 \pm 0.2$ & $1.2 \pm 0.2$ & .3 & $0.1 \pm 0.1$ \\
\hline \multirow[t]{2}{*}{$84-93 \%$} & Load $(\mathrm{kg})$ & $152.5 \pm 23.1$ & $159.2 \pm 21.8$ & $116.4 \pm 12.9$ & & $9.4 \pm 26$ & $6.0 \pm 9.5$ \\
\hline & $* \mathrm{BW}$ & $1.8 \pm 0.2$ & $1.9 \pm 0.4$ & $1.3 \pm 0.2$ & & $0.0 \pm 0.3$ & $0.1 \pm 0.1$ \\
\hline \multirow[t]{2}{*}{$94-99 \%$} & Load (kg) & $164.0 \pm 24.7$ & $174.6 \pm 20.1$ & $128.7 \pm$ & & $7.2 \pm 24.2$ & $7.9 \pm 8.0$ \\
\hline & $* \mathrm{BW}$ & $2.0 \pm 0.2$ & $2.0 \pm 0.4$ & $1.5=$ & $1.6 \pm 0.2$ & $0.0 \pm 0.3$ & $0.1 \pm 0.1$ \\
\hline \multirow[t]{2}{*}{$100 \%$} & Load (kg) & $169.5 \pm 26.5$ & $181.2 \pm 21.8$ & $135.2 \pm 11$ & $143.4 \pm 20.7$ & $11.8 \pm 25.4$ & $8.2 \pm 11.1$ \\
\hline & $* \mathrm{BW}$ & $1.9 \pm 0.3$ & $2.1 \pm 0.4$ & $1.6 \pm 0.2$ & $1.6 \pm 0.2$ & $0.1 \pm 0.3$ & $0.1 \pm 0.1$ \\
\hline
\end{tabular}

OLY, Olympic weightlifters; POW, Powerlifters; HBCOM, Comparison high-bar back squat; LBCOM, Comparison low-bar back-squat; BW, Body weight; 1RM, One repetition maximum; CI, Confidence interval. All data presented as mean \pm standard deviation. 
Table 2: Mean loads lifted effect sizes and percentage differences

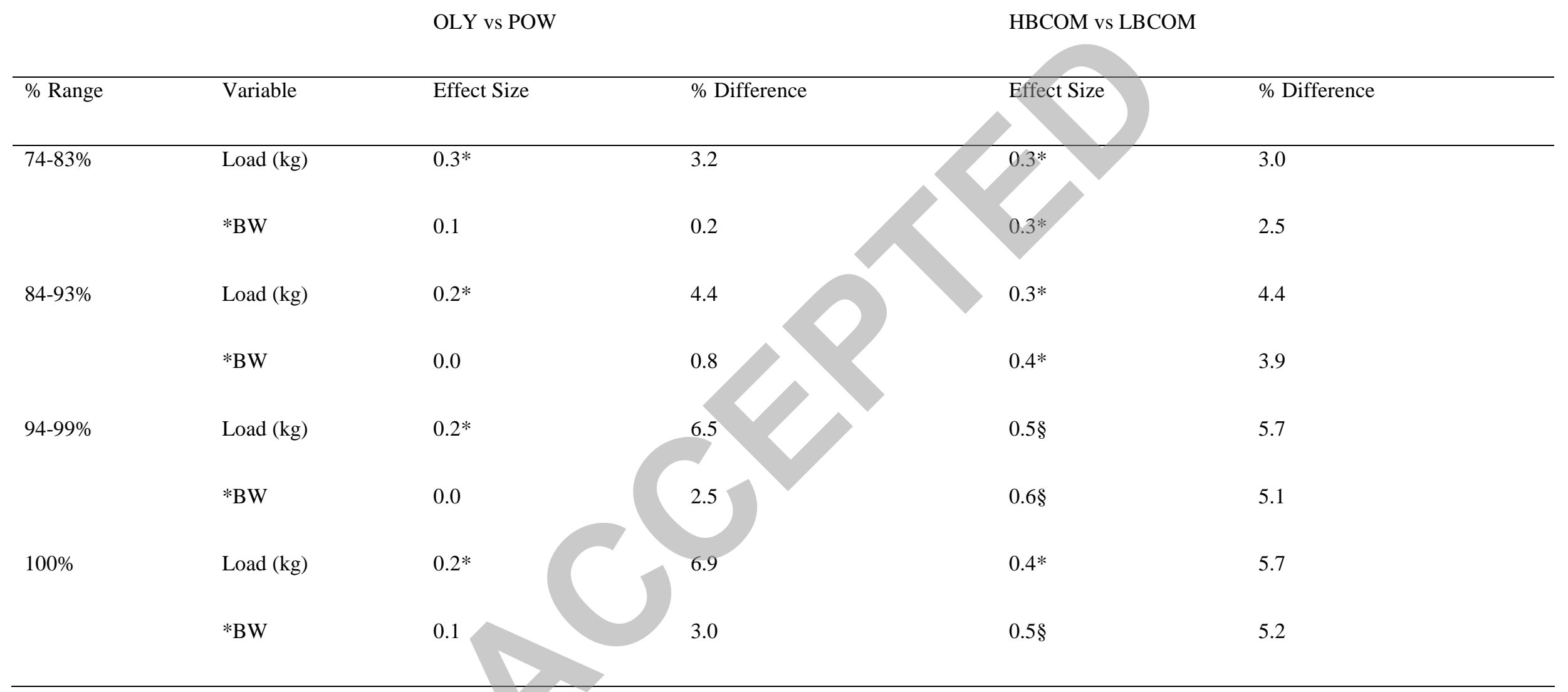

OLY, Olympic weightlifters; POW, Powerlifters; HBCOM, Comparison high-bar back squat; LBCOM, Comparison low-bar back-squat; BW, Body weight.

$*=$ Small effect $\mathrm{d} \geq 0.2 ; \S=$ Moderate effect $\mathrm{d} \geq 0.5$. 
Table 3: Distance of center of pressure to bar results

\begin{tabular}{|c|c|c|c|c|}
\hline$\%$ Range & OLY (mm) & POW (mm) & $\mathrm{HBCOM}(\mathrm{mm})$ & LBCOM (mm) \\
\hline $74-83 \%$ & $-19 \pm 42$ & $-44 \pm 31$ & $-60 \pm 45$ & $-57 \pm 18$ \\
\hline $84-93 \%$ & $-20 \pm 40$ & $-58 \pm 39$ & & $-72 \pm 25$ \\
\hline $94-99 \%$ & $-23 \pm 29$ & $-46 \pm 31$ & & $-59 \pm 38$ \\
\hline $100 \%$ & $-24 \pm 40$ & $-74 \pm 52$ & & $-51 \pm 18$ \\
\hline
\end{tabular}

OLY, Olympic weightlifters; POW, Powerlifters; HBCOM, Comparison high-bar back squat; LBCOM, Comparison low-bar back-squat. Negative number represents the bar a distance behind the center of pressure. All center of pressure data is presented as mean \pm standard deviation. 
Table 4: Kinematic results
High-Bar Back-Squat
Low-bar Back-Squat

\begin{tabular}{|c|c|c|c|c|c|c|c|c|c|c|}
\hline$\% 1 \mathrm{RM}$ & Joint & Variable & OLY & HBCOM & OLY vs HBCOM & OLY vs POW & POW & LBCOM & POW vs LBCOM & HBCOM vs LBCOM \\
\hline Range & & & Angle $\left(^{\circ}\right)$ & Angle $\left(^{\circ}\right)$ & Diff; $\pm 90 \%$ CI & Diff; $\pm 90 \%$ CI & & Angle & Diff; $\pm 90 \%$ CI & Diff; $\pm 90 \%$ CI \\
\hline \multirow[t]{7}{*}{$74-83 \%$} & \multirow[t]{2}{*}{ Hip } & Peak Flexion & $69 \pm 7$ & $64 \pm 5$ & $6 \pm 7$ & $8 \pm 10$ & $59 \pm 9$ & $61 \pm 4$ & $3 \pm 8$ & $3 \pm 3$ \\
\hline & & ROM & $100 \pm 8$ & $105 \pm 9$ & $5 \pm 10$ & & $109 \pm 11$ & $101 \pm 9$ & $9 \pm 12$ & $4 \pm 4$ \\
\hline & \multirow[t]{2}{*}{ Knee } & Peak Flexion & $54 \pm 7$ & $59 \pm 8$ & $3 \pm 9$ & & $62 \pm 11$ & $63 \pm 8$ & $1 \pm 11$ & $4 \pm 4$ \\
\hline & & ROM & $116 \pm 7$ & $110 \pm 11^{\wedge}$ & $3 \pm 11$ & & $114 \pm 12$ & $104 \pm$ & $8 \pm 13$ & $5 \pm 5$ \\
\hline & \multirow[t]{3}{*}{ Ankle } & Peak & $90 \pm 5$ & $88 \pm 6$ & \pm 6 & $2 \pm 5$ & $90 \pm 5$ & $90 \pm 8$ & $0 \pm 7$ & $2 \pm 4$ \\
\hline & & Dorsiflexion & & & & & & & & \\
\hline & & ROM & $33 \pm 4$ & 527 & $0 \pm 4$ & $1 \pm 6$ & $33 \pm 6$ & $30 \pm 4$ & $2 \pm 6$ & $2 \pm 3$ \\
\hline \multirow[t]{3}{*}{$84-93 \%$} & \multirow[t]{2}{*}{ Hip } & Peak Flexion & $69 \pm 9$ & $64 \pm 6^{\wedge}$ & $6 \pm 8$ & $6 \pm 11$ & $59 \pm 8$ & $61 \pm 3^{\wedge}$ & $3 \pm 7$ & $3 \pm 3$ \\
\hline & & ROM & $100 \pm 9$ & $105 \pm 10$ & $6 \pm 11$ & $8 \pm 11$ & $111 \pm 11$ & $99 \pm 9$ & $13 \pm 11$ & $5 \pm 5$ \\
\hline & Knee & Peak Flexion & $56 \pm 7$ & $61 \pm 8$ & $4 \pm 8$ & $7 \pm 11$ & $63 \pm 12$ & $67 \pm 5$ & $4 \pm 10$ & $6 \pm 6$ \\
\hline
\end{tabular}




\begin{tabular}{|c|c|c|c|c|c|c|c|c|c|c|}
\hline & & ROM & $114 \pm 7$ & $107 \pm 11$ & $5 \pm 10$ & $1 \pm 12$ & $113 \pm 13$ & $101 \pm 6$ & $12 \pm 12$ & $6 \pm 6$ \\
\hline & \multirow[t]{3}{*}{ Ankle } & Peak & $91 \pm 4$ & $90 \pm 6$ & $2 \pm 5$ & $2 \pm 5$ & $90 \pm 5$ & $91 \pm 7$ & $1 \pm 7$ & $1 \pm 3$ \\
\hline & & \multicolumn{9}{|l|}{ Dorsiflexion } \\
\hline & & ROM & $33 \pm 4$ & $30 \pm 5$ & $2 \pm 4$ & $2 \pm 6$ & & & $4 \pm 6$ & $0 \pm 2$ \\
\hline 94- & Hip & Peak Flexion & $71 \pm 10$ & $69 \pm 6^{\wedge}$ & $4 \pm 9$ & $12 \pm 12$ & & $61 \pm 5^{\wedge}$ & $2 \pm 9$ & $8 \pm 8$ \\
\hline \multirow[t]{6}{*}{$99 \%$} & & ROM & $98 \pm 10$ & $100 \pm 10$ & $4 \pm 11$ & & & \pm 10 & $9 \pm 14$ & $0 \pm 3$ \\
\hline & \multirow[t]{2}{*}{ Knee } & Peak Flexion & $56 \pm 7$ & $65 \pm 8$ & $8 \pm 9$ & & $62 \pm 12$ & $68 \pm 5$ & $5 \pm 10$ & $3 \pm 4$ \\
\hline & & ROM & $113 \pm 8$ & $103 \pm 12$ & $8 \pm 12$ & & $114 \pm 13$ & $101 \pm 7$ & $11 \pm 12$ & $6 \pm 6$ \\
\hline & \multirow[t]{3}{*}{ Ankle } & Peak & $90 \pm 5$ & $91 \pm 6$ & $1 \pm 6$ & & $90 \pm 5$ & $92 \pm 7$ & $2 \pm 7$ & $1 \pm 2$ \\
\hline & & Dorsiflexion & & & & & & & & \\
\hline & & ROM & $33 \pm 4$ & $28 \pm 4$ & $4 \pm 5$ & $1 \pm 6$ & $33 \pm 7$ & $29 \pm 3$ & $4 \pm 6$ & $1 \pm 2$ \\
\hline \multirow[t]{3}{*}{$100 \%$} & \multirow[t]{2}{*}{ Hip } & Peak Flexion & $71 \pm 9$ & $68 \pm 6^{1}$ & $3 \pm 8$ & $12 \pm 12$ & $59 \pm 10$ & $63 \pm 6^{\wedge}$ & $4 \pm 8$ & $5 \pm 5$ \\
\hline & & ROM & $97 \pm 10$ & $101 \pm 10$ & $4 \pm 10$ & $11 \pm 12$ & $109 \pm 13$ & $96 \pm 11$ & $13 \pm 13$ & $5 \pm 5$ \\
\hline & Knee & Peak Flexion & $56 \pm 7 *$ & $65 \pm 6^{* \wedge}$ & $9 \pm 9$ & $7 \pm 11$ & $63 \pm 12$ & $73 \pm 6^{\wedge}$ & $10 \pm 10$ & $7 \pm 7$ \\
\hline
\end{tabular}




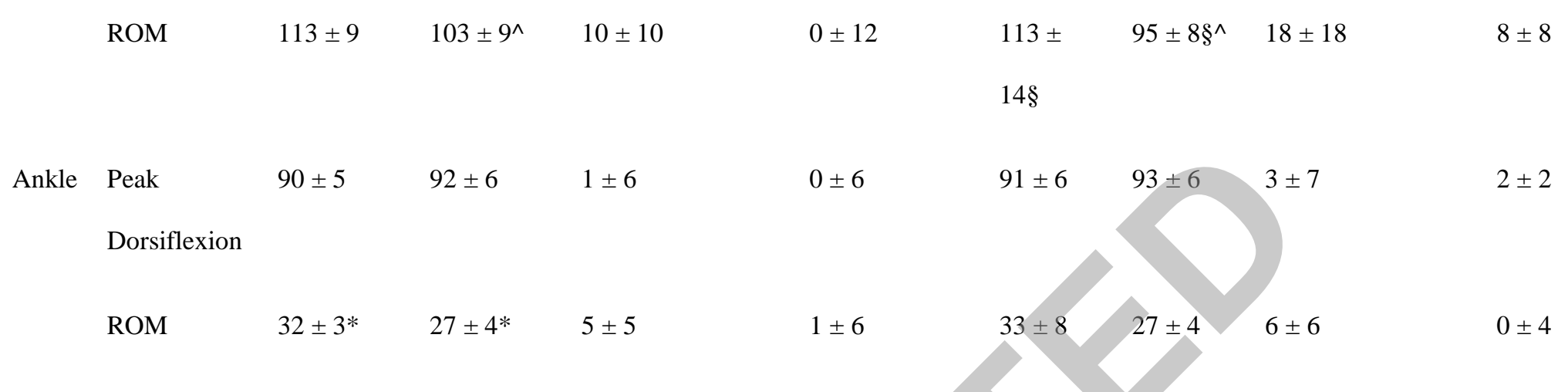

OLY, Olympic weightlifters; POW, Powerlifters; HBCOM, Comparison high-bar back-squat; LBCOM, Comparison low-bar back-squat; ROM, Range of motion; CI,

Confidence interval.

All angle data presented at mean \pm standard deviation. * ${ }^{*}<0.05$ OLY vs HBCOM; $\$$ p $<0.05$ POW vs LBCOM; ${ }^{\wedge}$ p $<0.05$ HBCOM vs LBCOM. 
Table 5: Kinematic effect sizes and percentage differences

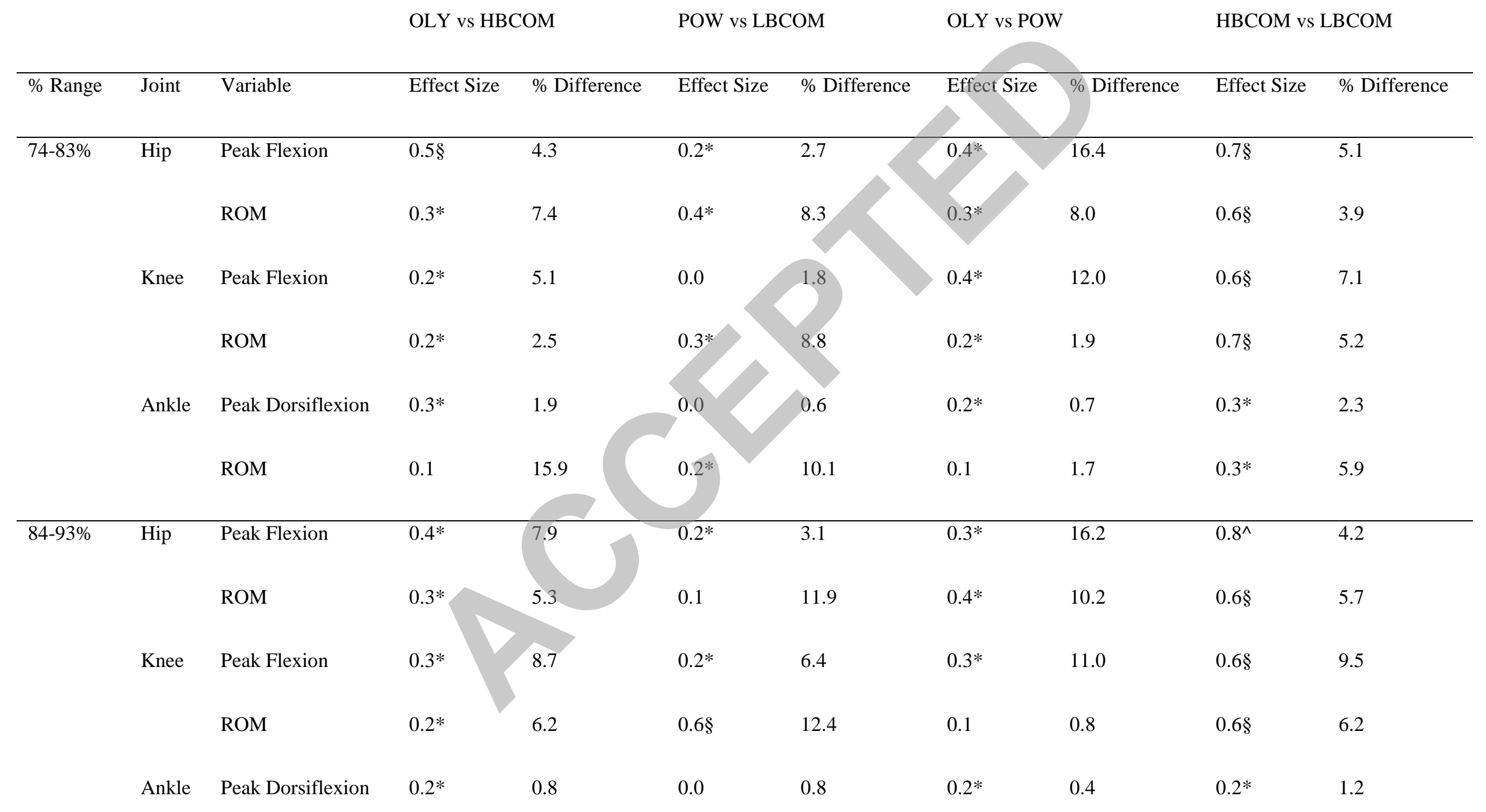




\begin{tabular}{|c|c|c|c|c|c|c|c|c|c|c|}
\hline & & $\mathrm{ROM}$ & $0.2^{*}$ & 10.2 & $0.3^{*}$ & 14.6 & $0.2^{*}$ & 2.4 & 0.0 & 1.5 \\
\hline \multirow[t]{4}{*}{$94-99 \%$} & Hip & Peak Flexion & $0.2 *$ & 2.4 & 0.1 & 2.9 & $0.6 \S$ & 19.5 & $2.3^{\wedge}$ & 11.8 \\
\hline & Knee & Peak Flexion & $0.4^{*}$ & 13.7 & $0.2^{*}$ & 7.9 & & 9.9 & $0.3^{*}$ & 4.0 \\
\hline & \multirow[t]{2}{*}{ Ankle } & Peak Dorsiflexion & 0.1 & 1.0 & 0.1 & 1.9 & 0.0 & 0.1 & $0.2^{*}$ & 0.9 \\
\hline & & ROM & $0.4^{*}$ & 15.4 & 0.3 & 15 & 0.1 & 1.9 & $0.2^{*}$ & 3.2 \\
\hline \multirow[t]{4}{*}{$100 \%$} & Hip & Peak Flexion & $0.2 *$ & 3.8 & & 6.6 & $0.7 \S$ & 20.7 & $1.3^{\wedge}$ & 7.9 \\
\hline & Knee & ROM & $0.6 \S$ & & $0.8^{\wedge}$ & 18.9 & 0.0 & 0.1 & $0.8^{\wedge}$ & 7.7 \\
\hline & \multirow[t]{2}{*}{ Ankle } & Peak Dorsiflexion & 0.1 & 1.3 & $0.2^{*}$ & 2.9 & 0.0 & 0.2 & $0.6 \S$ & 1.9 \\
\hline & & ROM & $0.7 \S$ & 18.3 & $0.5 \S$ & 22.0 & 0.1 & 1.9 & 0.0 & 1.1 \\
\hline
\end{tabular}

OLY, Olympic weightlifters; POW, Powerlifters; HBCOM, Comparison high-bar back-squat; LBCOM, Comparison low-bar back-squat; ROM, Range of motion.

$*=$ Small effect $\mathrm{d} \geq 0.2 ; \S=$ Moderate effect $\mathrm{d} \geq 0.5 ; \wedge=$ Large effect $\mathrm{d} \geq 0.8$. 
Table 6: Kinetic results 74-83\% 1RM

\begin{tabular}{|c|c|c|c|c|c|c|c|c|c|}
\hline Phase & \multirow{2}{*}{ Variable } & \multicolumn{4}{|c|}{ High-Bar Back-Squat } & \multicolumn{3}{|c|}{ Low-Bar Back-Squat } & HBCOM vs LBCOM \\
\hline & & & & Diff; $\pm 90 \%$ CI & Diff; $\pm 90 \% \mathrm{CI}$ & & & Diff; $\pm 90 \% \mathrm{CI}$ & Diff; $\pm 90 \%$ CI \\
\hline \multirow[t]{5}{*}{ Ecc } & Mean Bar $v$ & $0.51 \pm 0.13$ & $0.44 \pm 0.11$ & $0.09 \pm 0.19$ & $0.05 \pm 0.10$ & & $0.38 \pm$ & $0.20 \pm 0.20$ & $0.06 \pm 0.07$ \\
\hline & Peak $F v$ & $38 \pm 3^{*}$ & $26 \pm 4 *$ & $10 \pm 10$ & & $37 \pm 2.69 \S$ & $26 \pm 3 \S$ & $9 \pm 9$ & $1 \pm 2$ \\
\hline & $\left(\mathrm{N} \cdot \mathrm{s}^{-1}\right)$ & $1080^{*}$ & & & & & & & \\
\hline & RFD (0-100ms) & $3657 \pm$ & $1570 \pm 539$ & $2396 \pm 2396$ & $1319 \pm 1553$ & $3058 \pm$ & $1877 \pm 415$ & $1377 \pm 1641$ & $337 \pm 436$ \\
\hline & $\left(\mathrm{N} \cdot \mathrm{s}^{-1}\right)$ & $1788 ¥$ & & & & $1376 ¥$ & & & \\
\hline
\end{tabular}




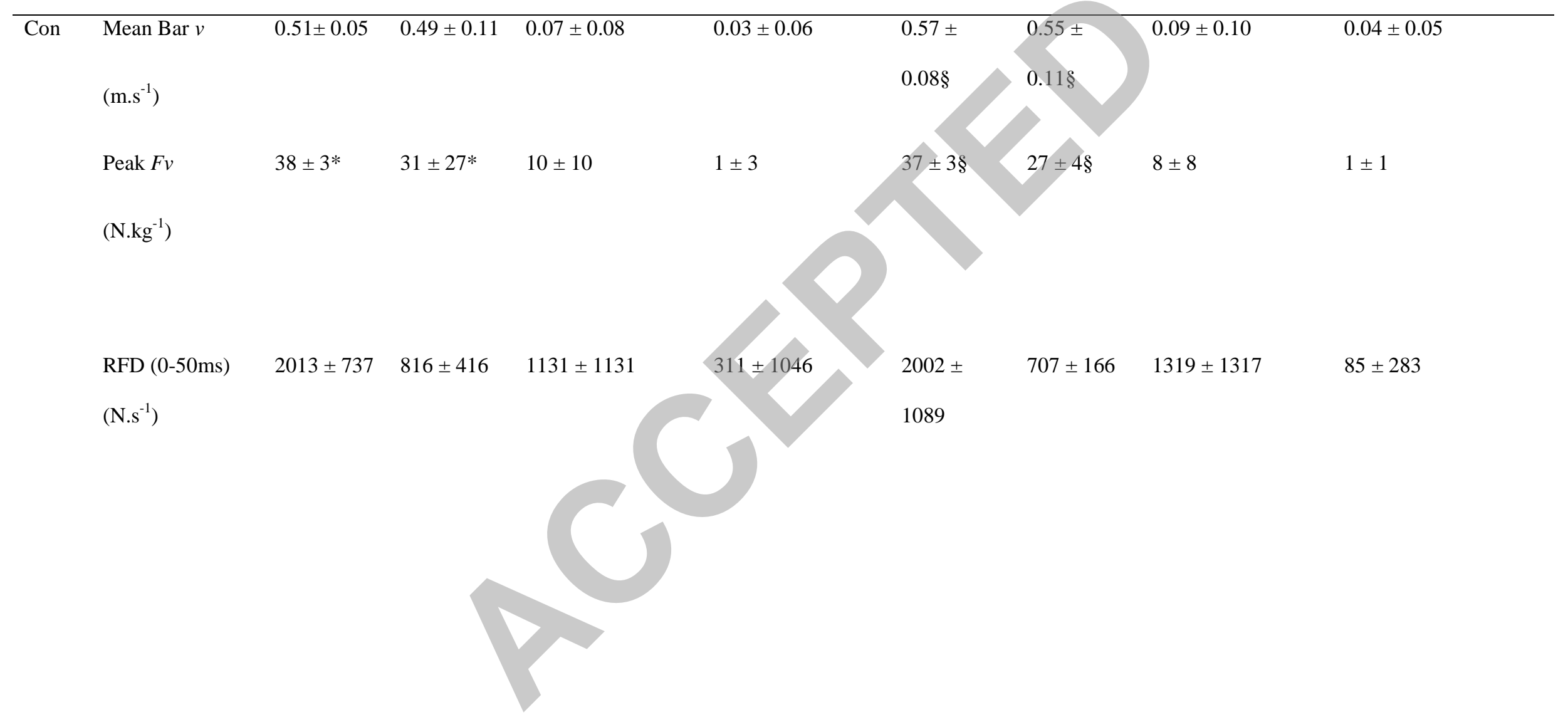


OLY, Olympic weightlifters; POW, Powerlifters; HBCOM, Comparison high-bar back-squat; LBCOM, Comparison low-bar back-squat; Ecc, Eccentric; Con, Concentric;

RFD, Rate of force development; $F v$, Vertical force; CI, Confidence interval. All kinetic data presented at mean \pm standard deviation. * $\mathrm{p}<0.05$ OLY vs HBCOM; $\S \mathrm{p}<0.05$ POW vs LBCOM; $¥ p<0.05$ OLY vs CON

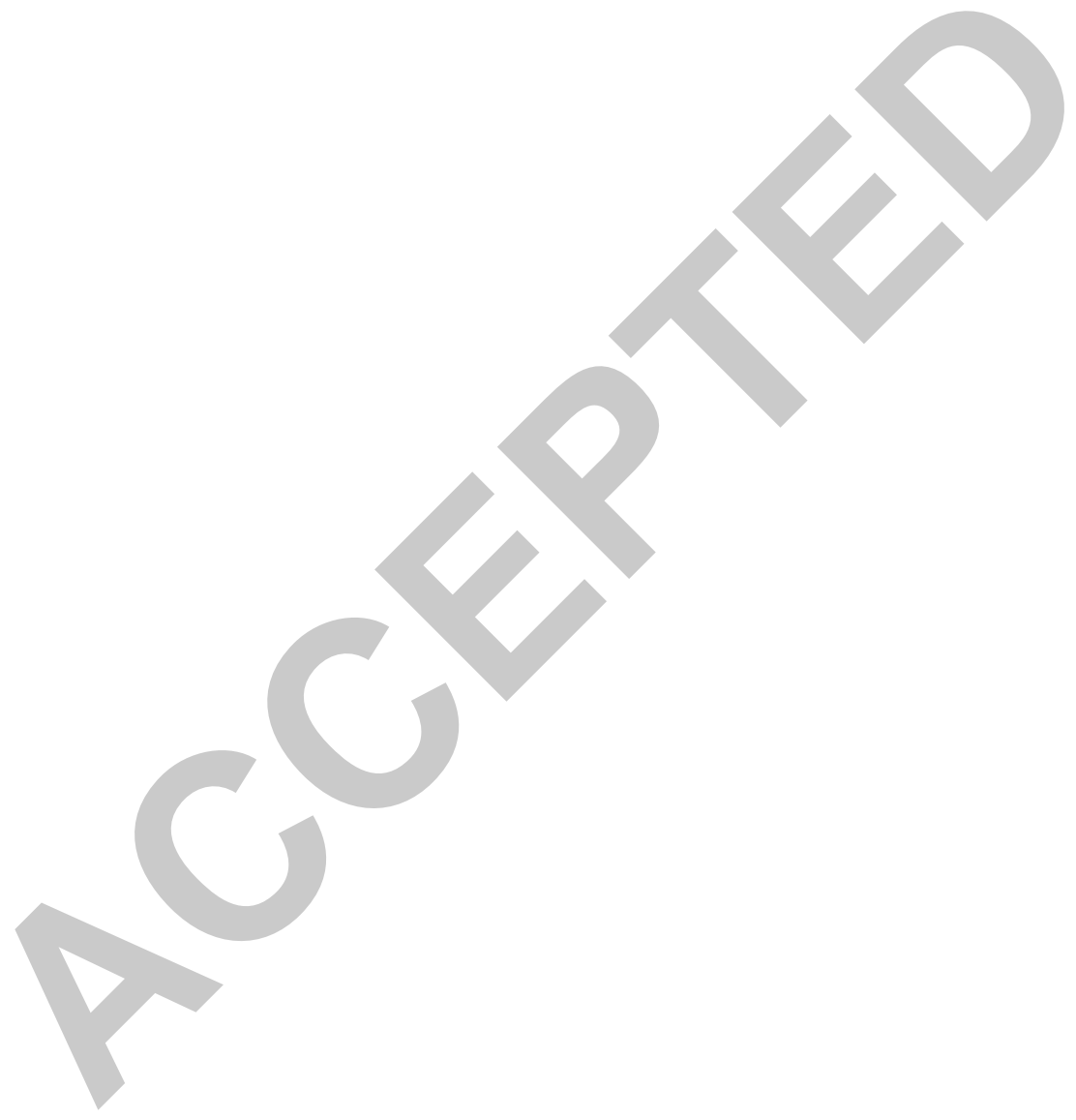


Table 7: Kinetic effect sizes and percentage differences 74-83\% 1RM

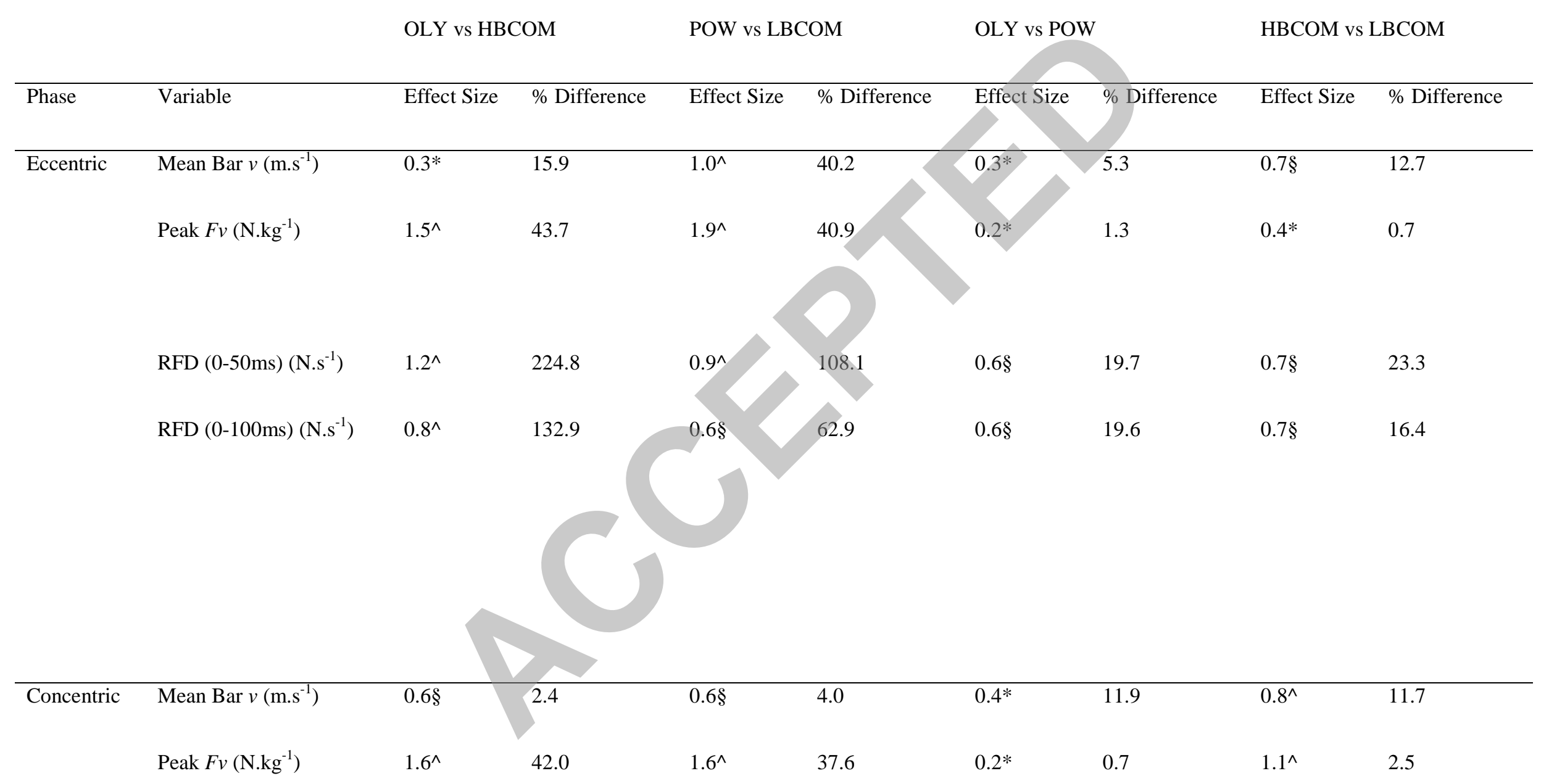




\begin{tabular}{|c|c|c|c|c|c|c|c|c|}
\hline RFD $(0-50 \mathrm{~ms})\left(\mathrm{N} . \mathrm{s}^{-1}\right)$ & $0.8^{\wedge}$ & 146.7 & $0.7 \S$ & 183.3 & $0.2^{*}$ & 0.6 & $0.3^{*}$ & 15.5 \\
\hline $\operatorname{RFD}(0-100 \mathrm{~ms})\left(\mathrm{N}^{-\mathrm{s}^{-1}}\right)$ & $0.6 \S$ & 123.6 & $0.8^{\wedge}$ & 161.2 & 0.1 & 5.4 & $0.2^{*}$ & 10.5 \\
\hline
\end{tabular}

OLY, Olympic weightlifters; POW, Powerlifters; HBCOM, Comparison high-bar back-squat; LBCOM, Comparison low-bar back-squat; ROM, Fv, Vertical force; RFD, Rate of force development. $*=$ Small effect $\mathrm{d} \geq 0.2 ; \S=$ Moderate effect $\mathrm{d} \geq 0.5 ; \wedge=$ Large effect $\mathrm{d} \geq 0.8$. 
Table 8: Kinetic results 84-93\% 1RM

High-Bar Back-Squat Low-Bar Back-Squat

\begin{tabular}{|c|c|c|c|c|c|c|c|c|c|}
\hline Phase & Variable & OLY & HBCOM & $\begin{array}{l}\text { OLY vs HBCOM } \\
\text { Diff; } \pm 90 \% \text { CI }\end{array}$ & $\begin{array}{l}\text { OLY vs POW } \\
\text { Diff; } \pm 90 \% \text { CI }\end{array}$ & POW & LBCOM & $\begin{array}{l}\text { POW vs } \\
\text { LBCOM Diff; } \\
\pm 90 \% \text { CI }\end{array}$ & $\begin{array}{l}\text { HBCOM vs } \\
\text { LBCOM Diff; } \\
\pm 90 \% \text { CI }\end{array}$ \\
\hline \multirow[t]{2}{*}{ Ecc } & $\begin{array}{l}\text { Mean Bar } v \\
\left(\mathrm{~m} \cdot \mathrm{s}^{-1}\right)\end{array}$ & $0.48 \pm 0.09$ & $0.39 \pm 0.08$ & $0.09 \pm 0.19$ & $0.00 \pm 0.10$ & $0.51 \pm 0.10 \S$ & $0.35 \pm 0.10 \S$ & $0.16 \pm 0.16$ & $0.04 \pm 0.04$ \\
\hline & $\begin{array}{l}\text { RFD }(0-50 \mathrm{~ms}) \\
\left(\mathrm{N} . \mathrm{s}^{-1}\right)\end{array}$ & $2258 \pm 943$ & $857 \pm 737$ & $1088 \pm 1188$ & $517 \pm 957$ & $1857 \pm 648 \S$ & $493 \pm 112 \S$ & $1425 \pm 1425$ & $362 \pm 745$ \\
\hline
\end{tabular}




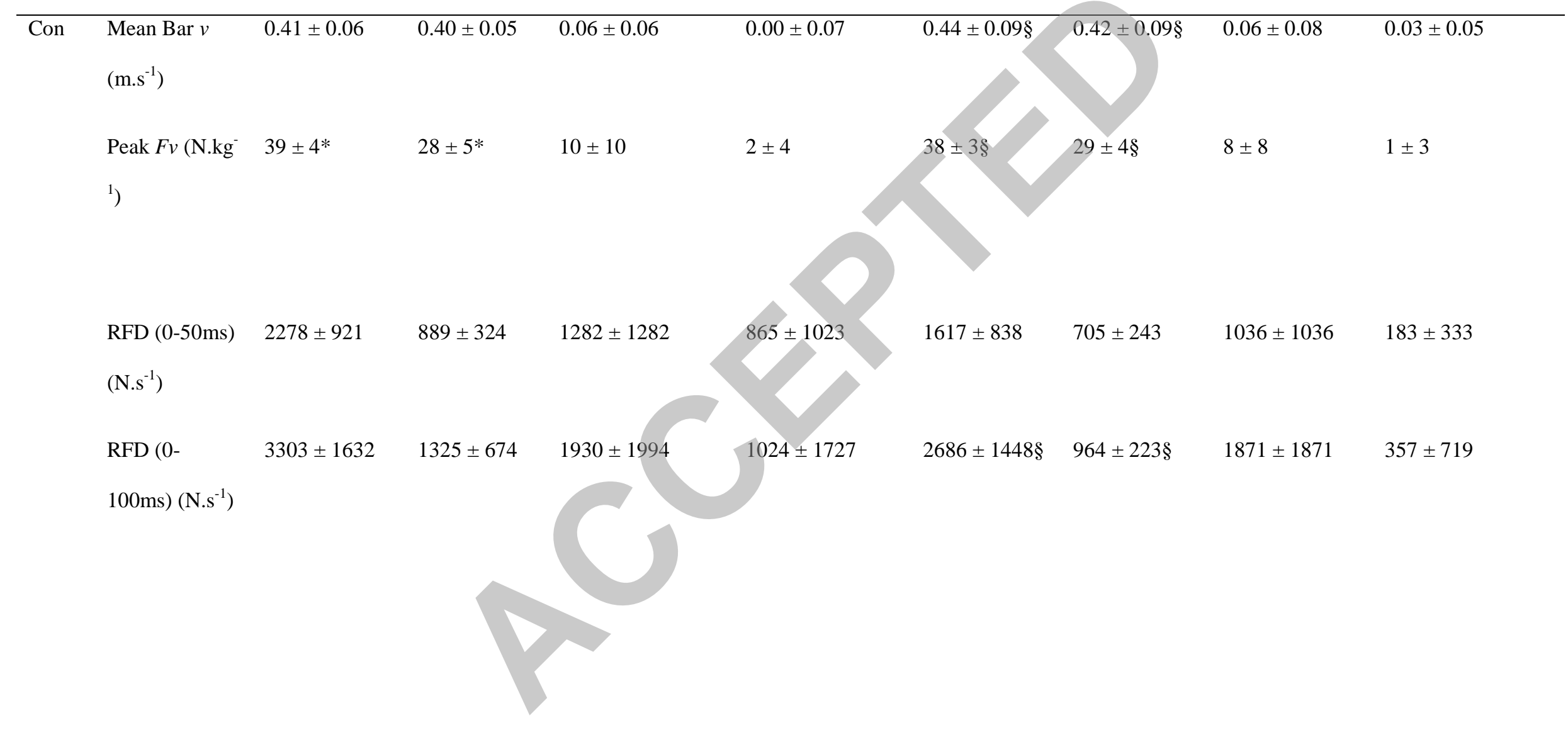


OLY, Olympic weightlifters; POW, Powerlifters; HBCOM, Comparison high-bar back-squat; LBCOM, Comparison low-bar back-squat; Ecc, Eccentric; Con, Concentric;

RFD, Rate of force development; $F v$, Vertical force; CI, Confidence interval. All kinetic data presented at mean \pm standard deviation. * $\mathrm{p}<0.05$ OLY vs HBCOM; $\S \mathrm{p}<0.05$ POW vs LBCOM.

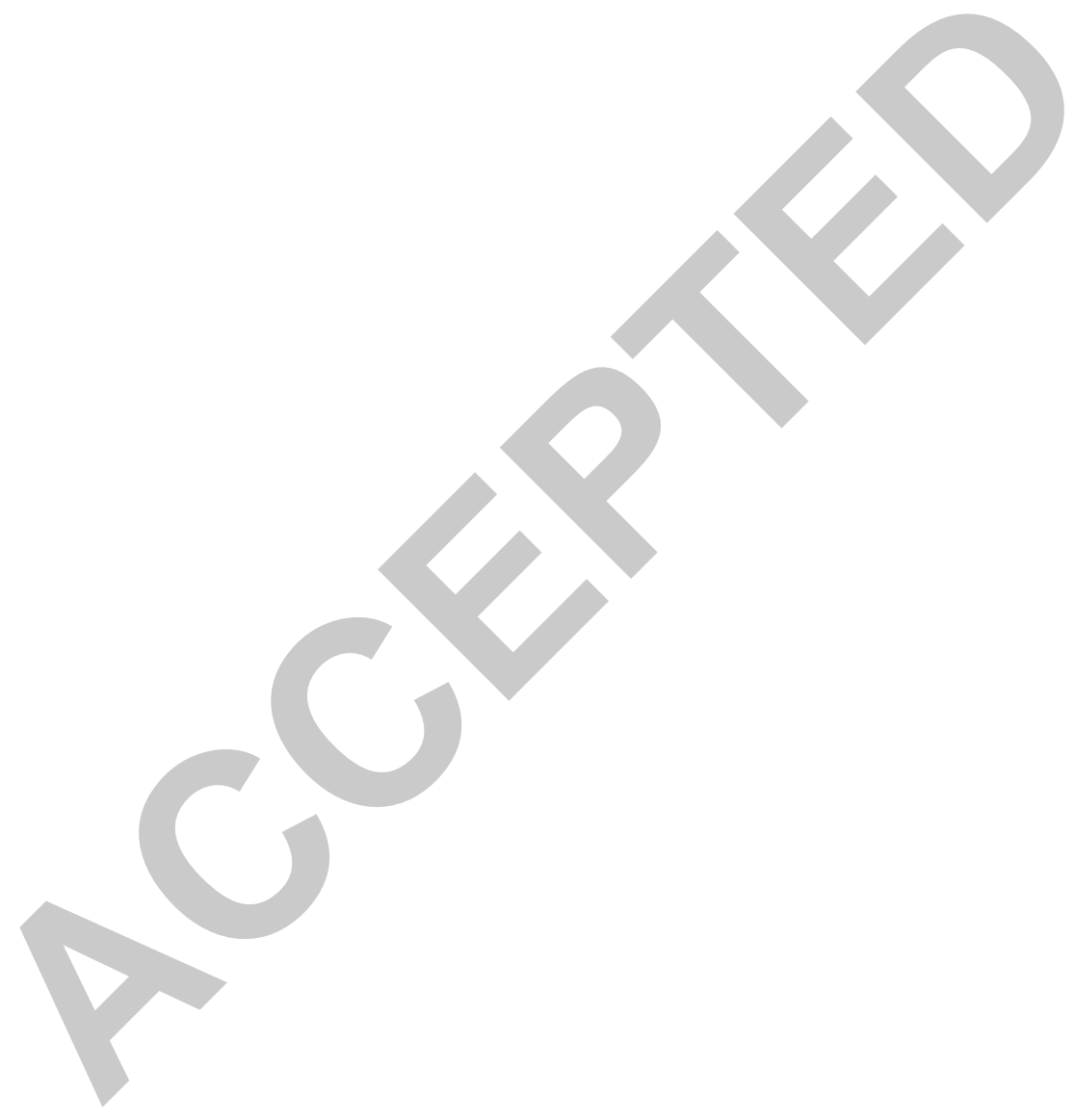


Table 9: Kinetic effect sizes and percentage differences 84-93\% 1RM

\begin{tabular}{|c|c|c|c|c|c|c|c|c|c|}
\hline & & OLY vs HE & $\mathrm{COM}$ & POW vs LE & $\mathrm{COM}$ & OLY vs PO & & HBCOM vs & LBCOM \\
\hline Phase & Variable & Effect Size & $\%$ Difference & Effect Size & \% Difference & Effect Size & \% Difference & Effect Size & $\%$ Difference \\
\hline \multirow{3}{*}{ Eccentric } & Peak $F v\left(\mathrm{~N}^{\mathrm{kg}} \mathrm{kg}^{-1}\right)$ & $1.5^{\wedge}$ & 42.5 & $2.1^{\wedge}$ & & $0.4^{*}$ & 4.3 & 0.1 & 2.1 \\
\hline & $\operatorname{RFD}(0-50 \mathrm{~ms})\left(\mathrm{N} . \mathrm{s}^{-1}\right)$ & $0.7 \S$ & 163.5 & & 276.5 & $0.4^{*}$ & 21.6 & $0.4^{*}$ & 73.7 \\
\hline & $\operatorname{RFD}(0-100 \mathrm{~ms})\left(\mathrm{N} \cdot \mathrm{s}^{-1}\right)$ & $0.6 \S$ & 9.9 & & 204.8 & $0.3^{*}$ & 17.8 & $0.4^{*}$ & 63.3 \\
\hline \multirow[t]{2}{*}{ Concentric } & Mean Bar $v\left(\mathrm{~m} \cdot \mathrm{s}^{-1}\right)$ & $0.7 \S$ & 5.5 & $0.5 \S$ & 5.1 & 0.0 & 6.8 & $0.4^{*}$ & 7.7 \\
\hline & Peak $F v\left(\mathrm{~N} \cdot \mathrm{kg}^{-1}\right)$ & $1.3^{\wedge}$ & 39.7 & $1.6^{\wedge}$ & 32.0 & $0.4^{*}$ & 3.6 & $0.3^{*}$ & 2.1 \\
\hline
\end{tabular}


RFD (0-50ms) (N.s $\left.{ }^{-1}\right)$

$0.8^{\wedge}$

156.3

$0.7 \S$

149.3 $0.9^{\wedge}$

$0.9^{\wedge}$
178.6
40.9

$0.4 *$
26.0

37.4

OLY, Olympic weightlifters; POW, Powerlifters; HBCOM, Comparison high-bar back-squat; LBCOM, Comparison low-bar back-squat; ROM, Fv, Vertical force; RFD, Rate of force development. * $=$ Small effect $\mathrm{d} \geq 0.2 ; \S=$ Moderate effect $\mathrm{d} \geq 0.5 ;{ }^{\wedge}=$ Large effect $\mathrm{d} \geq 0.8$. 
Table 10: Kinetic results 94-99\% 1RM

High-Bar Back-Squat $\quad$ Low-Bar Back-Squat

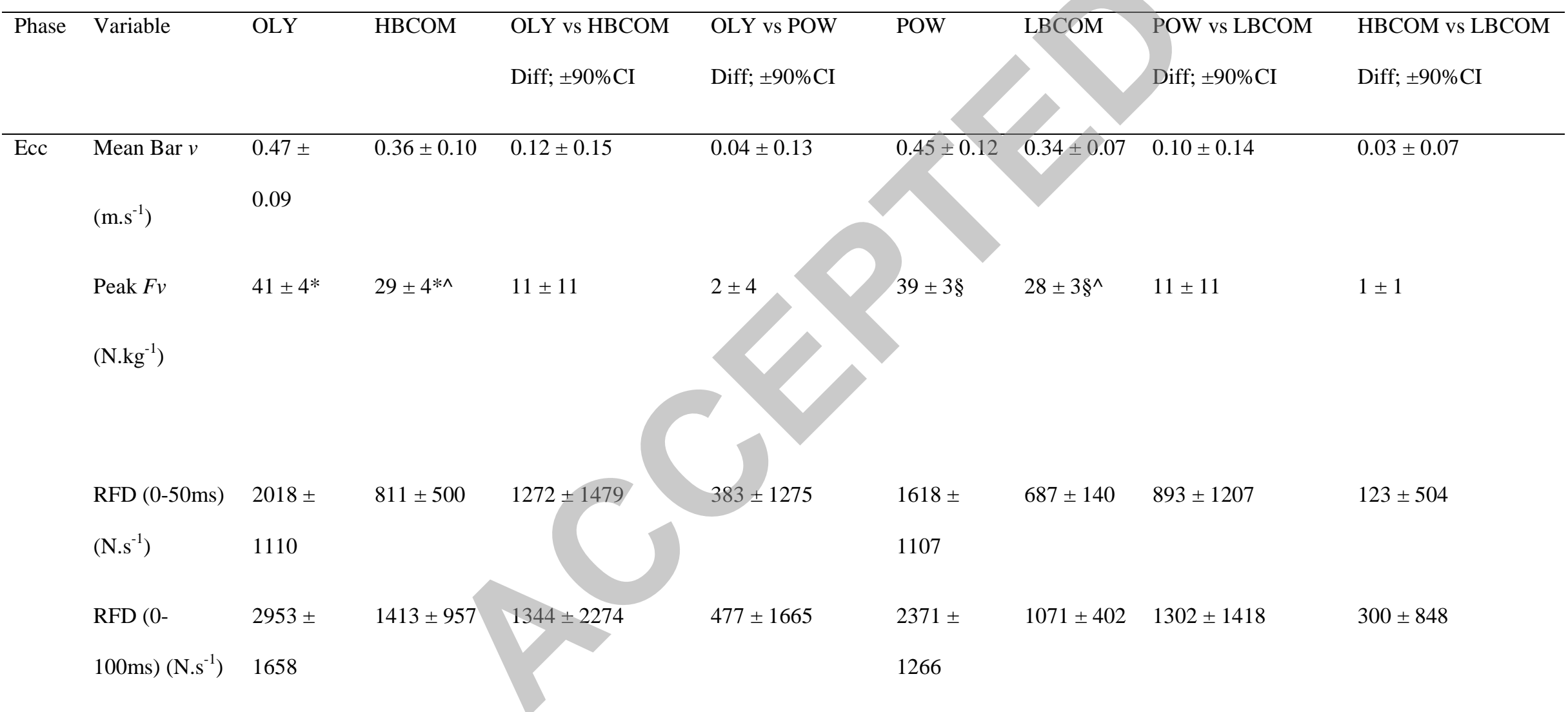




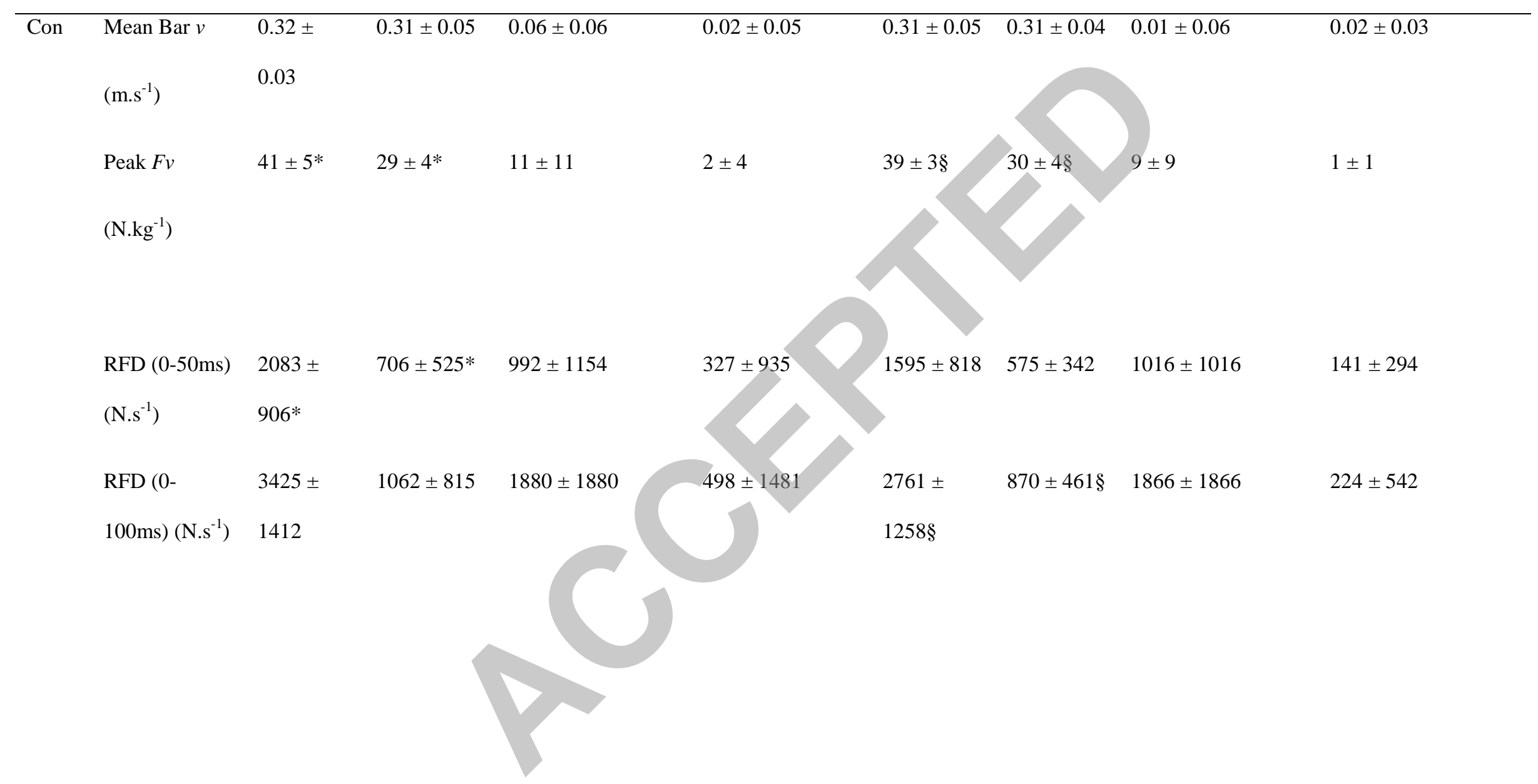

OLY, Olympic weightlifters; POW, Powerlifters; HBCOM, Comparison high-bar back-squat; LBCOM, Comparison low-bar back-squat; Ecc, Eccentric; Con, Concentric; RFD, Rate of force development; $F v$, Vertical force; CI, Confidence interval. All kinetic data presented at mean \pm standard deviation. * $\mathrm{p}<0.05$ OLY vs HBCOM; $§ \mathrm{p}<0.05$ POW vs LBCOM; ^ p < 0.05 HBCOM vs LBCOM. 
Table 11: Kinetic effect sizes and percentage differences 94-99\% 1RM

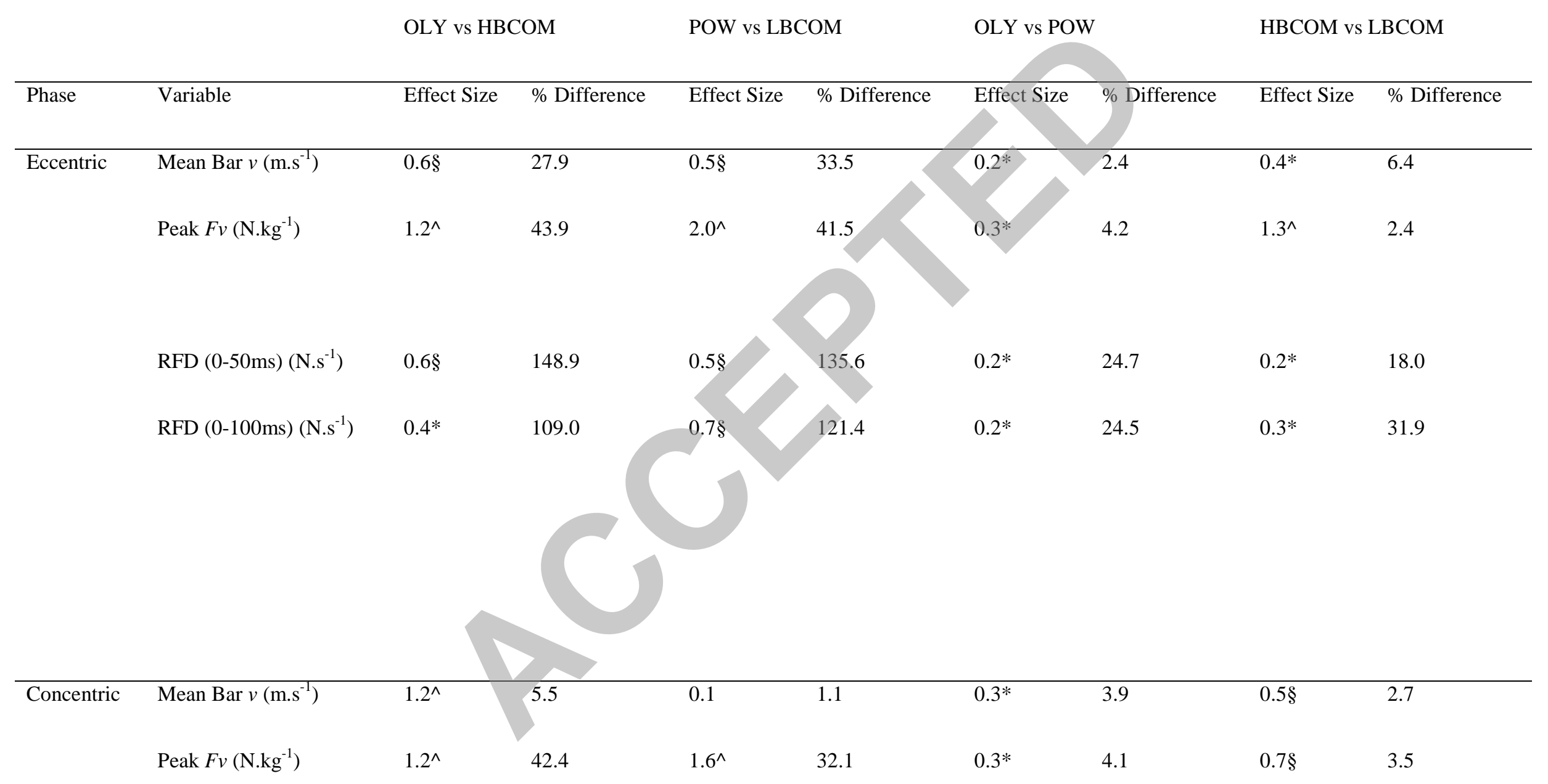




$\begin{array}{llllllll}\mathrm{RFD}(0-50 \mathrm{~ms})\left({\left.\mathrm{N} . \mathrm{s}^{-1}\right)}^{-1}\right. & 0.6 \S & 195.0 & 0.8^{\wedge} & 177.6 & 0.6 \S & 30.6 & 0.4^{*} \\ \mathrm{RFD}(0-100 \mathrm{~ms})\left(\mathrm{N} . \mathrm{s}^{-1}\right) & 0.7 \S & 222.3 & 0.9^{\wedge} & 217.2 & 0.2^{*} & 24.0 & 0.4^{*}\end{array}$

OLY, Olympic weightlifters; POW, Powerlifters; HBCOM, Comparison high-bar back-squat; LBCOM, Comparison low-bar back-squat; ROM, Fv, Vertical force; RFD, Rate of force development. $*=$ Small effect $\mathrm{d} \geq 0.2 ; \S=$ Moderate effect $\mathrm{d} \geq 0.5 ; \wedge=$ Large effect $\mathrm{d} \geq 0.8$. 
Table 12: Kinetic results $100 \%$ 1RM

High-Bar Back-Squat Low-Bar Back-Squat

\begin{tabular}{|c|c|c|c|c|c|c|c|c|c|}
\hline Phase & Variable & OLY & HBCOM & $\begin{array}{l}\text { OLY vs HBCOM } \\
\text { Diff; } \pm 90 \% \text { CI }\end{array}$ & $\begin{array}{l}\text { OLY vs POW } \\
\text { Diff; } \pm 90 \% \mathrm{CI}\end{array}$ & POW & LBCOM & $\begin{array}{l}\text { POW vs LBCOM } \\
\text { Diff; } \pm 90 \% \text { CI }\end{array}$ & $\begin{array}{l}\text { HBCOM vs LBCOM } \\
\text { Diff; } \pm 90 \% \text { CI }\end{array}$ \\
\hline \multirow{4}{*}{ Ecc } & $\left(\mathrm{m} \cdot \mathrm{s}^{-1}\right)$ & $0.09 *$ & $0.09^{*}$ & & & & $.06 \S$ & & \\
\hline & $\left(\mathrm{N} \cdot \mathrm{kg}^{-1}\right)$ & & & & & & & & \\
\hline & RFD (0-50ms) & $2240 \pm$ & $634 \pm 372 *$ & $1606 \pm 1606$ & $490 \pm 905$ & $1750 \pm$ & $375 \pm 337 \S$ & $1375 \pm 1375$ & $258 \pm 413$ \\
\hline & $100 \mathrm{~ms})\left(\mathrm{N} \cdot \mathrm{s}^{-1}\right)$ & 1681 & & & & $1485 \S$ & & & \\
\hline
\end{tabular}




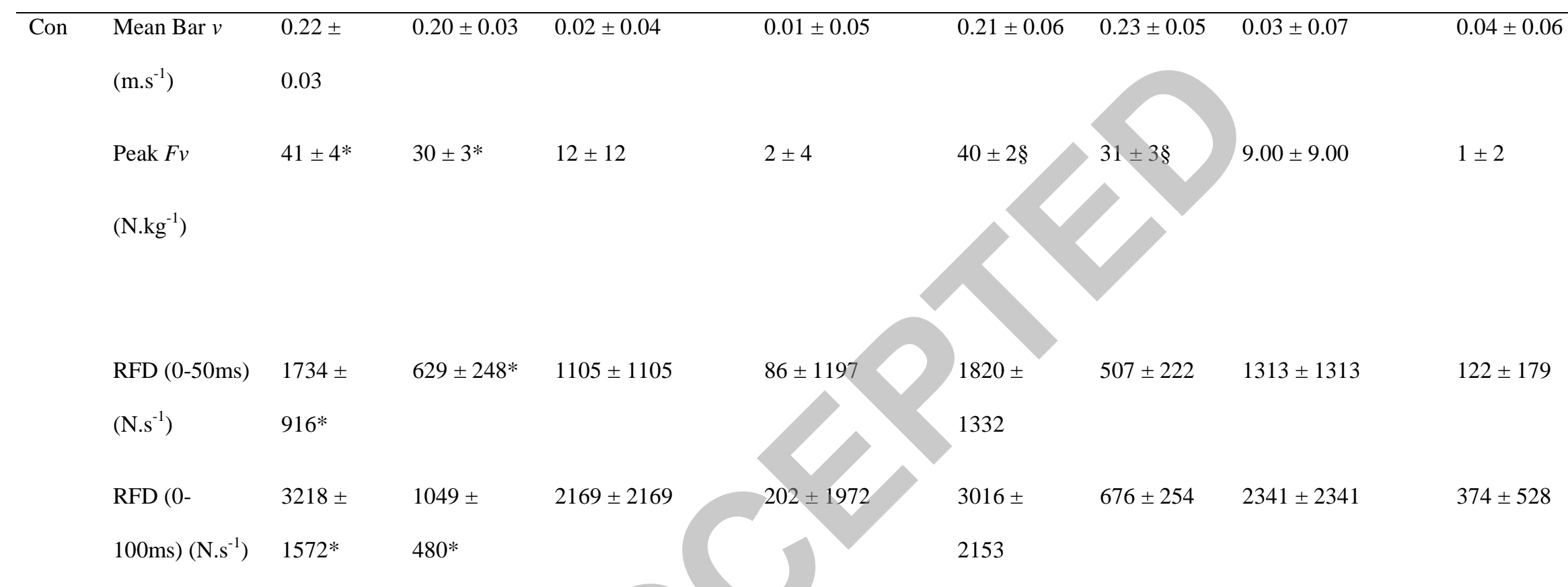

OLY, Olympic weightlifters; POW, Powerlifters; HBCOM, Comparison high-bar back-squat; LBCOM, Comparison low-bar back-squat; Ecc, Eccentric; Con, Concentric; RFD, Rate of force development; $F v$, Vertical force; CI, Confidence interval. All kinetic data presented at mean \pm standard deviation. $* \mathrm{p}<0.05$ OLY vs HBCOM; $§ \mathrm{p}<0.05$ POW vs LBCOM. 
Table 13: Kinetic effect sizes and percentage differences 100\% 1RM

\begin{tabular}{|c|c|c|c|c|c|c|c|c|c|}
\hline & & OLY vs HB & $\mathrm{OM}$ & POW vs LB & $\mathrm{OM}$ & OLY vs POV & & HBCOM vs & $\mathrm{B} \mathrm{CON}$ \\
\hline Phase & Variable & Effect Size & $\%$ Difference & Effect Size & $\%$ Difference & Effect Size & $\%$ Difference & Effect Size & $\%$ Difference \\
\hline \multirow[t]{4}{*}{ Eccentric } & Mean Bar $v\left(\mathrm{~m}^{-\mathrm{s}^{-1}}\right)$ & $0.9^{\wedge}$ & 40.0 & $0.9^{\wedge}$ & 46.4 & & 7.7 & $0.5 \S$ & 11.2 \\
\hline & Peak $F v\left(\mathrm{~N}^{\mathrm{kg}}{ }^{-1}\right)$ & $1.9^{\wedge}$ & 44.8 & $2.9^{\wedge}$ & .7 & & 3.5 & $0.2^{*}$ & 0.2 \\
\hline & RFD (0-50ms) $\left(\mathrm{N} . \mathrm{s}^{-1}\right)$ & $1.3^{\wedge}$ & 253.5 & 1.1 & & $0.4^{*}$ & 28.0 & $0.5 \S$ & 68.9 \\
\hline & $\operatorname{RFD}(0-100 \mathrm{~ms})\left(\mathrm{N}^{-\mathrm{s}^{-1}}\right)$ & $0.8^{\wedge}$ & 191.1 & & 9 & $0.2 *$ & 15.3 & $0.4^{*}$ & 55.6 \\
\hline \multirow[t]{2}{*}{ Concentric } & Mean Bar $v\left(\mathrm{~m} \cdot \mathrm{s}^{-1}\right)$ & $0.4^{*}$ & 9.9 & $0.3^{*}$ & 10.6 & 0.1 & 4.5 & $0.5 \S$ & 17.7 \\
\hline & Peak $F v\left(\mathrm{~N}^{\mathrm{kg}}{ }^{-1}\right)$ & $1.7^{\wedge}$ & 39.3 & $2.1^{\wedge}$ & 29.2 & $0.3^{*}$ & 3.2 & $0.7 \S$ & 4.5 \\
\hline
\end{tabular}




\begin{tabular}{|c|c|c|c|c|c|c|c|c|}
\hline RFD (0-50ms) (N.s $\left.{ }^{-1}\right)$ & $0.9^{\wedge}$ & 175.6 & $0.7 \S$ & 259.1 & 0.0 & 4.7 & $0.6 \S$ & 24.1 \\
\hline $\operatorname{RFD}(0-100 \mathrm{~ms})\left(\mathrm{N} \cdot \mathrm{s}^{-1}\right)$ & $1.0^{\wedge}$ & 206.7 & $0.8^{\wedge}$ & 346.5 & 0.1 & 6.7 & $0.6 \S$ & 55.3 \\
\hline
\end{tabular}

OLY, Olympic weightlifters; POW, Powerlifters; HBCOM, Comparison high-bar back-squat; LBCOM, Comparison low-bar back-squat; ROM, Fv, Vertical force; RFD, Rate of force development. * $=$ Small effect $\mathrm{d} \geq 0.2 ; \S=$ Moderate effect $\mathrm{d} \geq 0.5 ; \wedge=$ Large effect $\mathrm{d} \geq 0.8$. 

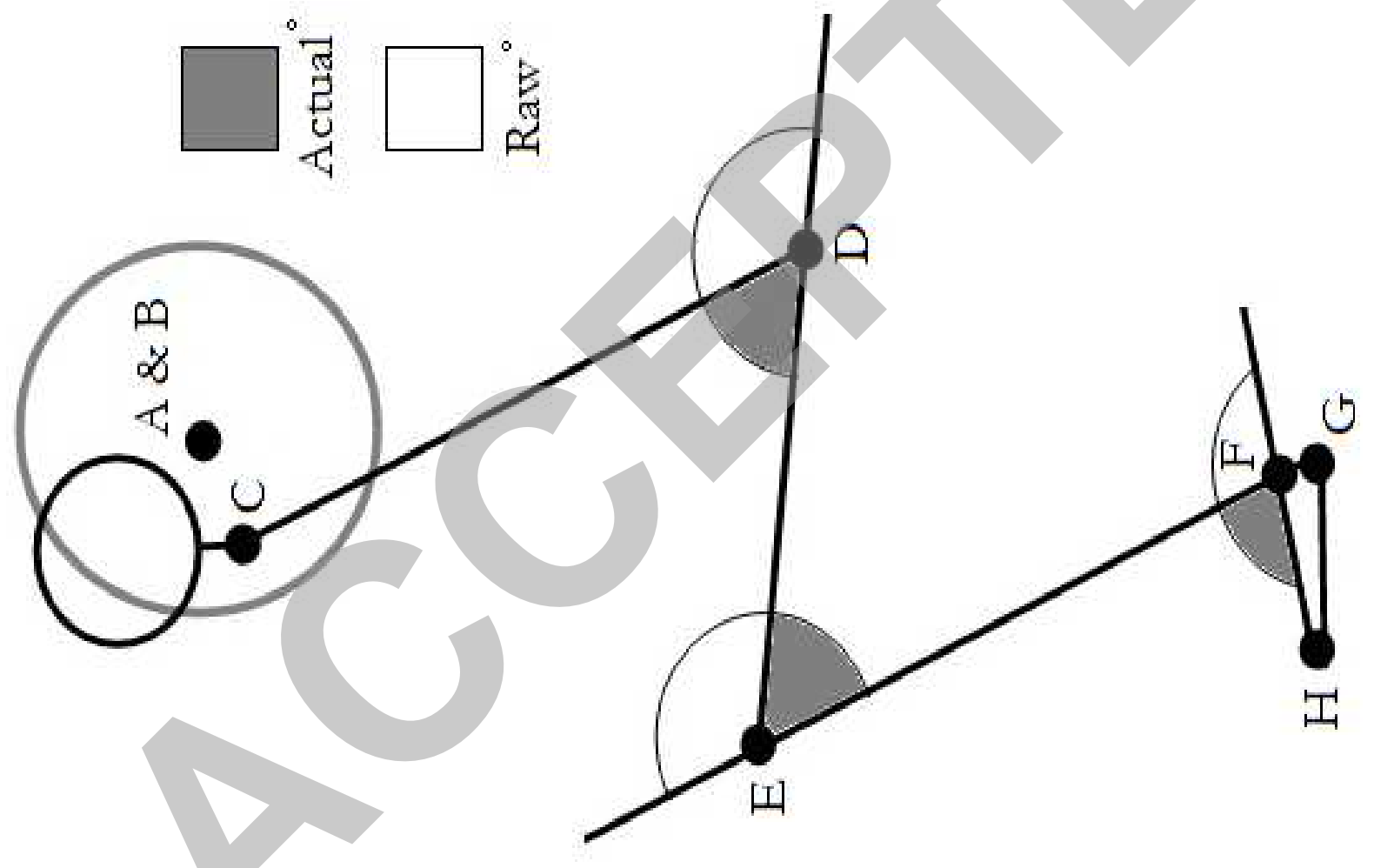


\begin{tabular}{|c|c|c|c|c|c|c|c|}
\hline Friday & Saturday & Sunday & Monday & Tuesday & Wednesday & Thursday & Friday \\
\hline $\begin{array}{c}\text { Familiarization } \\
\text { session } 1\end{array}$ & & & $\begin{array}{c}\text { Familiarization } \\
\text { session } 2\end{array}$ & & $\begin{array}{c}\text { 'Self-directed' } \\
\text { familiarization } \\
\text { session } 3 \\
\end{array}$ & & Testing session \\
\hline
\end{tabular}

